NBER WORKING PAPER SERIES

\title{
NOWCASTING AND PLACECASTING ENTREPRENEURIAL QUALITY AND PERFORMANCE
}

\author{
Jorge Guzman \\ Scott Stern \\ Working Paper 20954 \\ http://www.nber.org/papers/w20954 \\ NATIONAL BUREAU OF ECONOMIC RESEARCH \\ 1050 Massachusetts Avenue \\ Cambridge, MA 02138 \\ February 2015
}

This paper was prepared for the NBER/CRIW Measuring Entrepreneurial Businesses: Current Knowledge and Challenges conference, Washington, DC, December, 2014. We are thankful to David Audretsch, Pierre Azoulay, Erik Brynjolfsson, Georgina Campbell, Christian Catalini, Iain Cockburn, Mercedes Delgado, Catherine Fazio, Joshua Gans, Karen Mills, Fiona Murray, Abhishek Nagaraj, Ramana Nanda, Hal Varian, Ezra Zuckerman, Sam Zyontz, and the conference organizers John Haltiwanger, Erik Hurst, Javier Miranda, and Antoinette Schoar for comments and suggestions. We would also like to thank participants in NBER/CRIW pre-conference, the MIT Regional Entrepeneurship Acceleration Program, and seminar participants at the MIT Initiative on the Digital Economy, Micro@Sloan, and the 2014 NBER-AIEA Conference, and the 2014 DRUID Meetings. We thank Raymond J. Andrews for his superb development of the visualizations in Figures 3, 6, and 8. Carlos Garay provided RA support, and Alex Caracuzzo and MIT Libraries provided important data support. We are thankful to Patrick Fennelly and the Massachusetts Corporation Division for their help getting this data. We also acknowledge and thank the Jean Hammond (1986) and Michael Krasner (1974) Entrepreneurship Fund and the Edward B. Roberts (1957) Entrepreneurship Fund at MIT for financial support. All errors and omissions are of course our own. The views expressed herein are those of the authors and do not necessarily reflect the views of the National Bureau of Economic Research.

At least one co-author has disclosed a financial relationship of potential relevance for this research. Further information is available online at http://www.nber.org/papers/w20954.ack

NBER working papers are circulated for discussion and comment purposes. They have not been peerreviewed or been subject to the review by the NBER Board of Directors that accompanies official NBER publications.

(C) 2015 by Jorge Guzman and Scott Stern. All rights reserved. Short sections of text, not to exceed two paragraphs, may be quoted without explicit permission provided that full credit, including $(\subset$ notice, is given to the source. 
Nowcasting and Placecasting Entrepreneurial Quality and Performance

Jorge Guzman and Scott Stern

NBER Working Paper No. 20954

February 2015

JEL No. C43,C51,C81,E27,L25,L26,R12

\begin{abstract}
A central challenge in the measurement of entrepreneurship is accounting for the wide variation in entrepreneurial quality across firms. This paper develops a new approach for estimating entrepreneurial quality by linking the probability of a growth outcome (e.g., achieving an IPO or a significant acquisition) as a function of start-up characteristics observable at or near the time of initial business registration (e.g., the firm name or filing for a trademark/patent). Our approach allows us to characterize entrepreneurial quality at an arbitrary level of geographic granularity (placecasting) and in advance of observing the ultimate growth outcomes associated with any cohort of start-ups (nowcasting). We implement this approach in Massachusetts from 1988-2014, yielding several key findings. First, consistent with Guzman and Stern (2015), we find that a small number of observable start-up characteristics allow us to distinguish the potential for a significant growth outcome: in an out-of-sample test, more than $75 \%$ of growth outcomes occur in the top 5\% of our estimated quality distribution. Second, we propose two new economic statistics for the measurement of entrepreneurship: the Entrepreneurship Quality Index (EQI) and the Regional Entrepreneurship Cohort Potential Index (RECPI). We use these indices to offer a novel characterization of changes in entrepreneurial quality across space and time. For example, we are able to document changes in entrepreneurial quality leadership between the Route 128 corridor, Cambridge and Boston, as well as more granular assessments that allow us to distinguish variation in average entrepreneurial quality down to the level of individual addresses. Third, we find a high correlation between an index that depends only on information directly observable from business registration records (and so can be calculated on a real-time basis) with an index that allows for a two-year lag that allows the estimate of entrepreneurial quality to incorporate early milestones such as patent or trademark application or being featured in local newspapers. Finally, we find that the most significant "gap" between our index and the realized growth outcomes of a given cohort seem to be closely related to investment cycles: while the most successful cohort of Massachusetts start-ups was founded in 1995, the year 2000 cohort registered the highest estimated quality.
\end{abstract}

Jorge Guzman

MIT Sloan School of Management

100 Main Street, E62-343

Cambridge, MA 02142

jorgeg@mit.edu

Scott Stern

MIT Sloan School of Management

100 Main Street, E62-476

Cambridge, MA 02142

and NBER

sstern@mit.edu 
"When any estimate is examined critically, it becomes evident that the maker, wittingly or unwittingly, has used one or more criteria of productivity. The statistician who supposes that he can make a purely objective estimate of national income, not influenced by preconceptions concerning the 'facts', is deluding himself; for whenever he includes one item or excludes another he is implicitly accepting some standard of judgment, his own or that of the compiler of his data. There is no escaping this subjective element in the work, or freeing the results from its effects".

Simon Kuznets.

National Income and its Composition, 1919-1938. Volume I. p. 3. (1941)

A central challenge of economic measurement arises from the inevitable gap between the theoretical rationale for an economic statistic and the phenomena being measured. Not simply an abstract concern, the ability to reliably and systematically link economic phenomena closely linked to productivity or economic growth is central to the ability of policymakers and researchers to evaluate policy or understand the drivers of economic performance.

These concerns are particularly salient in the measurement of entrepreneurship. Though entrepreneurship is often cited by economists and policymakers as central to the process of economic growth and performance (Schumpeter, 1942; Aghion and Howitt, 1992; Davis and Haltiwanger, 1992), measuring the "type" of entrepreneurship that seems likely to be associated with overall economic performance has been challenging. While studies of high-performance ventures primarily rely on samples that select a population of firms that have already achieved relatively rare milestones such as the receipt of venture capital, broader population studies of entrepreneurs and small business emphasize the low growth prospects of the average selfemployed individual (Hamilton, 2000; Hurst and Pugsley, 2011). As emphasized by Schoar (2010) in her synthesis of entrepreneurship on a global basis, there is a gap between the small 
number of transformative entrepreneurs whose ambition and capabilities are aligned with scaling a dynamic and growing business and the much more prevalent incidence of subsistence entrepreneurs whose activities are an (often inferior) substitute to low-wage employment.

It is important to emphasize that, though luck and unobserved ability undoubtedly play an important role in the entrepreneurial process, the gap in the outcomes and impact of different ventures also reflect ex ante fundamental differences in the potential of those ventures. While most "Silicon Valley"-type start-ups fail, their intention at the time of founding is to build a company with a high level of equity and/or employment growth (and often are premised on exploiting new technology or serving an entirely new customer segment). At the same time, the ambition and potential for even a "successful" local business is often quite modest, and might involve building a firm of a small number of employees and yielding income comparable to that which would have been earned through wage-based employment. In other words, as emphasized by Hurst and Pugsley (2010), though policymakers and theory often treat entrepreneurs as a homogenous group (at least from an ex ante perspective), entrepreneurs seem to be very heterogeneous in terms of the ambition and potential of their ventures. For the purposes of measurement, then, it is critical that we not only capture variation in entrepreneurial outcomes but also develop the capability to measure variation in the quality of entrepreneurial ventures from the time of founding.

Building on Guzman and Stern (2015), ${ }^{1}$ this paper develops a novel approach to the estimation of entrepreneurial quality that allows us to characterize regional clusters of

\footnotetext{
${ }^{1}$ Guzman and Stern (2015) introduces the distinction between entrepreneurial quality and quantity and the broad methodology in this paper of predicting growth outcomes from start-up characteristics available at or around the time of founding for a population sample of business registrants. At some points in describing the methodology and data, we draw from that paper to accurately describe our procedures and sample. This paper significantly extends and expands upon Guzman and Stern (2015) in several respects, including the formal definition and proposal for two new economic statistics (EQI and RECPI), the inclusion of additional start-up characteristics variables such as media mentions and a
} 
entrepreneurship at an arbitrary level of granularity (placecasting), and examine the dynamics of entrepreneurial quality over time on a near real-time basis (nowcasting). Our approach combines three interrelated insights. First, because the challenges to reach a growth outcome as a sole proprietorship are formidable, a practical requirement for any growth-oriented entrepreneur is business registration (as a corporation, partnership, or limited liability company). We take advantage of the public nature of business registration records (in this paper, from the state of Massachusetts from 1988-2014) to define a population sample of entrepreneurs observed at a similar (and foundational) stage of the entrepreneurial process. Second, moving beyond simple counts of business registrants (Klapper, Amit, and Guillen, 2010), we are able to measure characteristics related to entrepreneurial quality at or close to the time of registration. For example, we can measure start-up characteristics such as whether the founders name the firm after themselves (eponymy), whether the firm is organized in order to facilitate equity financing (e.g., registering as a corporation or in Delaware), or whether the firm acquires or develops measurable innovations (e.g., a patent or trademark). Third, we leverage the fact that, though rare, we observe meaningful growth outcomes for some firms (e.g., those that achieve an IPO or high-value acquisition within six years of founding), and are therefore able to estimate the relationship between these growth outcomes and start-up characteristics.

We apply our approach in the context of Massachusetts from 1988-2014². First, consistent with Guzman and Stern (2015) (which uses our approach on California data), we find that a

measure for serial founders, extending the method to a second state (Massachusetts), evaluating the dynamics over time at both the state level as well at more granular regional levels, and explicitly comparing an index that can be computed in real-time versus one that incorporates information from early milestones over the first two years of the venture.

${ }^{2}$ Our current results depend on a cross section of firms using the locations listed as of November, 2014, rather than their founding location. In a series of tests, we find the probability of changing location to be low - for example, for cohorts from 2008-2012, the probability of changing zip codes is 0.12 . We are currently undertaking a data effort to account, to the extent feasible using public data, for the full history of location changes for all firms. 
small number of characteristics allow us to develop a robust predictive model that distinguishes firm quality. In an out-of-sample test, we find that $77 \%$ of realized growth outcomes occur in the top $5 \%$ of our estimated quality distribution (and nearly $50 \%$ in the top $1 \%$ of the estimated quality distribution). Importantly, we find that there is significant benefit in predictive accuracy from including multiple start-up characteristics (relative to, say, exclusively relating quality to a single characteristic such as applying for a patent), and, at the same time, the quantitative significance of different start-up characteristics are roughly similar in our sample here and our sample of California firms in Guzman and Stern (2015).

We then use these estimates to propose two new economic statistics for the measurement of entrepreneurship: the Entrepreneurship Quality Index (EQI) and the Regional Entrepreneurship Cohort Potential Index (RECPI). EQI is a measure of average quality within any given group of firms, and allows for the calculation of the probability of a growth outcome for a firm within a specified population of start-ups. RECPI multiples EQI and the number of start-ups within a given geographical region (e.g., a town or even the state of Massachusetts). Whereas EQI compares entrepreneurial quality across different groups (and so facilitates apples-to-apples comparisons across groups of different sizes), RECPI allows the direct calculation of the expected number of growth outcomes from a given start-up cohort within a given regional boundary.

We use these indices to offer a novel characterization of changes in entrepreneurial quality across space and time. We start with an overall assessment of Massachusetts, where RECPI increased dramatically during the second half of the 1990s, and then falls dramatically in the wake of the dot-com crash. RECPI then increased by more than $25 \%$ from its low in 2003 through 2012. We find that RECPI has predictive power: while there is no meaningful 
relationship between the pattern of growth outcomes and the number of new firms (i.e., a measure of quantity), RECPI at the county-year level has a strong quantitative and statistical relationship with the number of realized growth outcomes.

We then turn to our placecasting applications, where we characterize entrepreneurial quality at different levels of geographic granularity (but do not directly use information about the location itself). We document striking variation in the level of average entrepreneurial quality across different Massachusetts towns: the area around Boston has a much higher average level of entrepreneurial quality than the rest of the state, and there is striking variation within the Boston metro area, with Kendall Square, the northeast Route 128 corridor and the Boston Innovation District registering a very high level of average entrepreneurial quality. Over time, we document a striking change in entrepreneurial quality leadership as the Route 128 corridor has ceded EQI leadership to Cambridge. We are also able to offer more granular assessments, including comparing the areas immediately surrounding MIT / Kendall Square versus Harvard Square, and illustrating the micro-geography of entrepreneurial quality with an address-level visualization of the area immediately surrounding MIT.

We then examine the potential for nowcasting entrepreneurial quality, where we evaluate whether it is possible to make timely entrepreneurial quality predictions in advance of observing the ultimate growth outcomes associated with any cohort of start-ups. We specifically compare an index which relies only on start-up characteristics immediately observable at the time of business registration (name, Delaware registration, etc) with an index that allows for a two-year lag in order to incorporate early milestones such as patent or trademark application or being featured in local newspapers. Our results suggest that, though there is information that is 
gleaned from allowing for a lag, a nowcasted EQI is feasible and closely correlated with a more patient index.

Finally, we begin to consider the relationship between our measures and issues of theoretical or policy interest. Specifically, we find that the most significant "gap" between our index and the realized growth outcomes of a given cohort seem to be closely related to investment cycles: while the most successful cohort of Massachusetts start-ups was founded in 1995 , the year 2000 cohort registered the highest estimated quality. This finding is particularly important in the light of recent work on capital market cycles, the need for follow-on financing and innovative entrepreneurship (Nanda and Rhodes-Kropf, 2013; Nanda and Rhodes-Kropf, 2014). Though we are cautious in interpreting our results, our results are consistent with the idea that an important loss from variation in the level of risk capital financing is the lack of follow-on investment for precisely the cohort of ventures that actually registered the highest overall potential impact. More generally, consistent with earlier studies of the concentration of innovation such as Audretsch and Feldman (1996) and Furman, Porter and Stern (2002), our findings highlight the idea that, relative to the overall level of entrepreneurial activity, entrepreneurial quality is highly clustered in both space and time. Uncovering why entrepreneurial quality is concentrated remains an important topic for future research.

The rest of this paper proceeds as follows. We motivate our approach by discussing the need for a measure of entrepreneurial quality in Section II, and then present a methodology for constructing such a measure in Section III. Section IV introduces the data, and Sections V and VI present our key findings. A final section concludes. 


\section{Why is the Measurement of Entrepreneurial Quality Important?}

Our motivation for developing an index of entrepreneurial quality stems from a growing agreement within entrepreneurship scholars that while new firms seem to have a positive effect in regional economic growth on average (Davis and Haltiwanger, 1992; Haltiwanger, Jarmin and Miranda, 2013; Kortum and Lerner, 2000; Glaeser, Kerr, and Kerr, 2014), there is very significant heterogeneity across firms from the time of their founding, and only a very small fraction of start-ups seem to be driving the economy-wide benefits from entrepreneurship (Kerr, Nanda, and Rhodes-Kropf, 2014). As emphasized by Schoar, even if entrepreneurship has a net positive effect, policy efforts that aim to increase the supply of entrepreneurship without regard to quality could have a negative economic effect: "I argue that unless we understand the differences between those two types of entrepreneurs more clearly, many policy interventions may have unintended consequences and may even have an adverse impact on the economy." (Schoar, 2010; also see Hurst and Pugsley, 2010, Lerner, 2010, and Decker, Haltiwanger, Jarmin, and Miranda, 2014, for further discussion).

While there is increasing understanding of the importance of accounting for heterogeneity among entrepreneurs in the measurement of entrepreneurship, developing systematic measures of entrepreneurial quality has been challenging. In the area of entrepreneurial finance, researchers have often proceeded by simply examining samples of firms that have reached relatively rare milestones such as venture capital: while this facilitates the examination of the dynamics of high-potential firms, it nonetheless creates a disconnect between these small samples of selected firms and the overall population of start-up firms. ${ }^{3}$ At the same

\footnotetext{
${ }^{3}$ Self selection into the sample can result in a different type of selectivity. For example, the Startup Genome Project is a
} 
time, researchers have attempted to use publicly available data to develop specific indices of entrepreneurship, often at the regional level. Most of these indices have focused either on measures of entrepreneurial quantity (e.g., the Kauffman Index of Entrepreneurial Activity measures the rate of start-ups per capita using data from the Current Population Survey, and work by Leora Klapper and co-authors has provided benchmarking data for the rate of business registration across countries and time (Klapper, Amit, and Guillen, 2010), or on surveys that measure entrepreneurial attention, attitudes, or entrepreneurial activity (with the Global Entrepreneurship Monitor being the most influential and systematic effort based on surveys on a global basis (see Amoros and Bosma, 2014)). While these efforts have provided significant insight into the overall rate and attitudes towards entrepreneurial activity, these approaches have yet to directly address the interplay between the heterogeneity among entrepreneurs and the process of economic growth. Finally, research exploiting establishment-level data such as the Longitudinal Business Data (or the more aggregated Business Dynamics Statistics) have been able to document the role of entrepreneurship in job creation (e.g., emphasizing the importance of young firms rather than small firms in that process), and also highlighting an observed reduction in the rate of business dynamism in the United States over time (Haltiwanger, 2012; Decker, Haltiwanger, Jarmin, and Miranda, 2014; Hathaway and Litan, 2014a). But, as emphasized by Hathaway and Litan, the challenge in directly incorporating heterogeneity is a measurement problem: "The problem is that it is very difficult, if not impossible, to know at the

private effort to characterize regional start-ups aiming to address challenges of measuring the nature of start-up activity (Reister, 2014). However, the data they have gathered through self-submission and curated methods is very far from comprehensive. For example, in the Cambridge Innovation Center at 1 Broadway, in Cambridge, MA, Startup Genome identifies only 9 (presumably active) firms at the time of writing, while business registration records show 229 new firms at this address between 2007 and 2012. 
time of founding whether or not firms are likely to survive and/or grow." (Hathaway and Litan, 2014b).

Establishing a measurement framework for entrepreneurial quality would not simply be of interest for policymakers but would also allow for the direct assessment of key questions in entrepreneurship. For example, while clusters of entrepreneurship such as Silicon Valley or Boston are associated with a disproportionate share of companies that achieve a meaningful growth outcome (e.g., an IPO or acquisition), is this due simply to the fact that these areas are home to higher quality ventures or is there a separate impact of being located in a fertile entrepreneurial ecosystem? How does the quality of entrepreneurship vary across different types of founders (e.g., men versus women, or other demographic distinctions)? Finally, how does entrepreneurial quality vary with investment cycles (i.e., how does the level of entrepreneurial quality change during an investment boom, and what happens to high-quality entrepreneurial ventures that are founded just before an investment slowdown)? A measure of entrepreneurial quality could also be used to evaluate the impact of specific policy changes and programs, and also evaluate the role of institutions that impact some start-ups but not others. More generally, systematic measurement of entrepreneurial quality has the potential to serve as a tool for a broad range of questions relating to the causes and consequences of entrepreneurship.

\section{Methodology}

Building on this motivation, we now develop a novel methodology for estimating entrepreneurial quality for a population sample of start-ups at the time of founding, and propose preliminary candidates for two novel economic statistics to track and evaluate regional entrepreneurial performance: an Entrepreneurial Quality Index (EQI), a measure of the average 
quality of new firms, and a Regional Entrepreneurship Cohort Potential Index (RECPI), equal to the average quality of new firms multiplied by the number of new firms within a given cohortregion. Our approach combines three interrelated elements: the ability to observe a population sample of entrepreneurs, a procedure to estimate entrepreneurial quality for each start-up at the firm level, and a procedure to aggregate across quality into regional indices.

Data Requirements. A first requirement for a timely and granular index of entrepreneurial quality is an unbiased (ideally population) sample of new firms, and the ability to identify the quantity and quality of entrepreneurship of new cohorts on a timely basis. ${ }^{4}$ As discussed further in the Data section, we exploit publicly available business registration records to satisfy this first requirement. Since business registration is a practical (and straightforward) requirement for growth, the sample of business registrants in a given time period composes a meaningful cohort of start-ups for which one could evaluate quantity (the number of business registrants, or the number of business registrants of a certain type) as well as quality (by assessing the underlying quality of each business registrant in a standardized way).

Estimating Entrepreneurial Quality. To assess quality (at any level of granularity), we must first be able to estimate entrepreneurial quality for any given firm. To do so, we take advantage of the fact that, both directly within business registration records as well as through other publicly available data sources (such as the patent and trademark record, the news media, etc), we are able to potentially observe a set of "start-up characteristics." The central challenge is to develop a systematic approach that allows one to rank different start-ups based on these start-up characteristics. We do so by creating a mapping between a meaningful growth outcome

\footnotetext{
${ }^{4}$ Limiting the sample to firms having achieved a meaningful intermediate outcome (e.g., the receipt of venture capital) will inevitably conflate the process of selection into the intermediate outcome (which itself is likely to be changing over time and location) with the variation in underlying quality of ventures across time and location.
} 
(observed of course with a lag) and the characteristics observable at or near the time of founding. More precisely, for a firm $i$ born in region $r$ at time $t$, with start-up characteristics $X_{i, r, t}$, we observe a growth outcome $g_{i, r, t+s} s$ years after founding and estimate:

$$
\theta_{i, r, t}=1000 \times P\left(g_{i, r, t+s} \mid X_{i, r, t}\right)=1000 \times f\left(\alpha+\beta X_{i, r, t}\right)
$$

Using this predictive model, we are able to predict quality as the probability of achieving a growth outcome given start-up characteristics at birth, and so estimate entrepreneurial quality as $\hat{\theta}_{i, r, t} .^{5}$ To operationalize this idea, we draw on standard approaches in predictive modeling and divide our sample into three separate elements: a training sample, a test sample, and a prediction sample. The training sample is composed of the majority of observations for which we can observe both start-up characteristics and the growth outcome (i.e., the observable growth sample ends $s$ years prior to the present) and is the sample we use to estimate (1). ${ }^{6}$ We are then able to use the remaining data from the observable growth sample to conduct out-of-sample validation of our estimates (and of course are able to draw these samples multiple times to evaluate the robustness of our results to alternative draws of both samples). Finally, we are able to construct a prediction sample in which we observe start-up characteristics but have not yet observed the growth outcome. As long as the process by which start-up characteristics map to growth remain stable over time (an assumption which is itself testable), we are able to then develop an estimate for entrepreneurial quality even for very recent cohorts. In particular, we can examine the tradeoff between relying exclusively on start-up characteristics immediately observable at the time of business registration (which will allow one to create real-time statistics) with estimates

\footnotetext{
${ }^{5}$ While there exist several data mining methods to build a predictive model (including linear regression, binary regression, and neural networks), our methodology uses a logit regression, which performs well in quality of predictions (relative to a linear probability model) while still allowing interpretability of the economic magnitudes and significance of the coefficients for the measures used (Pohlman and Leitner, 2003).

${ }^{6}$ We reserve $30 \%$ of the sample for which we observe both the growth outcome and start-up characteristics for the test sample.
} 
that allow for a lag in order to incorporate early milestones such as patent or trademark application or being featured in local newspapers.

Calculating an Entrepreneurial Quality Index. To create an index of entrepreneurial quality for any group of firms (e.g., all the groups within a particular cohort or a group of firms satisfying a particular condition), we simply take the average quality within that group. Specifically, in our regional analysis, we define the Entrepreneurial Quality Index (EQI) as an aggregate of quality at the region-year level by simply estimating the average of $\theta_{i, r, t}$ over that region:

$$
E Q I_{r, t}=\frac{1}{N_{r, t}} \sum_{i \in\left\{I_{r, t}\right\}} \theta_{i, r, t}
$$

where $\left\{I_{r, t}\right\}$ represents the set of all firms in region $r$ and year $t$, and $N_{r, t}$ represents the number of firms in that region-year. To ensure that our estimate of entrepreneurial quality for region $r$ reflects the quality of start-ups in that location rather than simply assuming that start-ups from a given location are associated with a given level of quality, we exclude any location-specific measures $X_{r, t}$ from the vector of observable start-up characteristics.

Three particular features of EQI are notable. First, while the general form of $E Q I_{r, t}$ is a panel format, it is possible to construct a cross-sectional distribution of quality at a moment in time (i.e., $E Q I_{r, t_{0}}$ ) to facilitate analyses such as spatial mapping. Second, the level of geographical aggregation is arbitrary: while the discussion of a "region" may connote a large geographic area, it is possible to calculate EQI at the level of a city, ZIP code, or even individual addresses. Finally, we can extend EQI in order to study an arbitrary grouping of firms (i.e., we do not need to select exclusively on geographic boundaries). For example, we can examine startups whose founder share a common demographic characteristic (e.g., sex), or firms that undertake a specific strategic action (e.g., engage in crowdfunding). 
The Regional Entrepreneurship Cohort Potential Index (RECPI). From the perspective of a given region, the overall potential for a cohort of start-ups requires combining both the quality of entrepreneurship in a region and the number of firms in such region (a measure of quantity). To do so, we define RECPI as simply $E Q I_{r, t}$ multiplied by the number of firms in that region-year:

$$
\operatorname{RECPI}_{r, t}=E Q I_{r, t} \times N_{r, t}
$$

Since our index multiplies the average probability of a firm in a region-year to achieve growth (quality) by the number of firms, it is, by definition, the expected number of growth events from a region-year given the start-up characteristics of a cohort at birth. Under the assumption of excluding regional effects (e.g., agglomeration economies) or time-based effects (e.g., changes in available financing), our index can be interpreted as a measure of the "potential" of a region given the "intrinsic" quality of firms at birth, which can then be affected by the impact of the entrepreneurial ecosystem, or shocks to the economy and the cohort between the time of founding and a growth outcome.

Assessing the Merit of our Quality Estimates. Our methodology estimates the quality of new firms through a predictive model of probability of achieving a growth outcome, and as such the predictive accuracy of the model must be evaluated before relying on its estimates to draw economic inference. Specifically, given concerns about the potential for over-fitting (Taddy, 2013), we reserve $30 \%$ of the observable growth outcome sample in order to conduct out-ofsample validation. In particular, we conduct the analysis multiple times to evaluate the robustness of our estimates to the sample from which it is drawn, and also plot the share of realized outcomes (in the test sample) associated with different percentiles of our estimated 
quality distribution. Robustness of the coefficients to different samples, and a model with strong predictive accuracy in out-of-sample testing are stronger candidates as economic statistics.

\section{Data}

As mentioned earlier, our analysis leverages publicly available business registration records, a potentially rich and systematic data for entrepreneurship and business dynamics. Business registration records are public records created when individuals register a business. This analysis focuses on the state of Massachusetts from 1988-2014 (see Appendix I for a short description and discussion of these records). During the time of our sample, it was possible to register several types of businesses: corporations, limited liability companies, limited liability partnerships, and general partnerships. While it is possible to found a new business without business registration (e.g., a sole proprietorship), the benefits of registration are substantial, including limited liability, protection of the entrepreneur's personal assets, various tax benefits, the ability to issue and trade ownership shares, credibility with potential customers, and the ability to deduct expenses. Furthermore, all corporations, partnerships, and limited liability must register with the state in order to take advantage of these benefits: the act of registering the firm triggers the legal creation of the company. As such, these records form the population of Massachusetts businesses that take a form that is a practical prerequisite for growth. ${ }^{7}$

Concretely, our analysis draws on the complete population of firms satisfying one of the following conditions: (a) a for-profit firm whose jurisdiction is in Massachusetts or (b) a for-

\footnotetext{
${ }^{7}$ This section draws on Guzman and Stern (2015), where we introduce the use of business registration records in the context of entrepreneurial quality estimation.
} 
profit firm whose jurisdiction is in Delaware but whose principal office address is in Massachusetts. In other words, our analysis excluded non-profit organizations as well as companies whose primary location is external to Massachusetts. Applied over the years 19882014 , the resulting dataset is composed of 541,666 observations $^{8}$. For each observation we construct variables related to (a) the growth outcome for each start-up, (b) start-up characteristics based on business registration observables and (c) start-up characteristics based on external observables that can be linked directly to the startup. Table 1 reports the summary statistics, both for the overall sample (divided out by our estimation and prediction sample periods) and conditional on whether the firm achieved a growth outcome or not.

Growth. The growth outcome utilized in this paper, Growth, is a dummy variable equal to 1 if the startup achieves an initial public offering (IPO) or is acquired at a meaningful positive valuation within 6 years of registration ${ }^{9}$. Both outcomes are drawn from Thomson Reuters SDC Platinum. ${ }^{10}$ We observe 462 positive growth outcomes for the 1988-2005 startup cohorts (used in all our regressions), yielding a mean of Growth of 0.0014 . The median acquisition price is $\$ 77$ million (ranging from a minimum of $\$ 11.9$ million at the $5^{\text {th }}$ percentile to $\$ 1.92$ billion at the $95^{\text {th }}$ percentile). ${ }^{11}$

\footnotetext{
${ }^{8}$ The number of firm births in our sample is substantially higher than the US Census Longitudinal Business Database (LBD), done from tax records. For Massachusetts in the period 2003-2012, the LBD records an average of 9,450 new firms per year and we record an average of 24,066 firm registrations. While the reasons for this difference are still to be explored, there are at least two reasons which we expect will be in part causing this difference: (i) partnerships and LLCs who do not have income during the year do not file a tax returns and are thus not included in the LBD, and (ii) firms that have zero employees are not included in the LBD.

${ }^{9}$ Our results are robust to changes in the time allowed for a firm to achieve growth. See Guzman and Stern (2015, Supplementary Materials) for a subset of those robustness tests.

${ }_{10}$ While the coverage of IPOs is likely to be nearly comprehensive, the SDC dataset excludes some acquisitions. However, though the coverage of significant acquisitions is not universal in the SDC dataset, previous studies have "audited" the SDC data to estimate its reliability, finding a nearly 95\% accuracy (Barnes et al, 2014).

${ }^{11}$ In our main results, we assign acquisitions with an unrecorded acquisitions price as a positive growth outcome, since an evaluation of those deals suggests that most reported acquisitions were likely in excess of $\$ 5$ million. All results are robust to the assignment of these acquisitions as equal to a growth outcome.
} 
Start-Up Characteristics. The core of the empirical approach is to map growth outcomes to observable characteristics of start-ups at or near the time of business registration. We develop two types of measures: (a) measures based on business registration observables, and (b) measures based on external indicators of start-up quality that are observable at or near the time of business registration. We review each of these in turn.

Measures Based on Business Registration Observables. We construct ten measures based on information observable in the business registration records. Four are measures that we anticipate are associated with firm potential, four are dummy variables based on the industry cluster most closely linked to the start-up, and two are associated with measures of serial entrepreneurship to capture the underlying quality of the founder.

We first create two binary measures that relate to how the firm is registered, Corporation, whether the firm is a corporation rather than an LLC or partnership, and Delaware Jurisdiction, whether the firm is registered in Delaware. Corporation is an indicator equal to 1 if the firm is registered as a corporation and 0 if it is registered either as an LLC or partnership. ${ }^{12}$ In the period of 1988 to $2005,0.19 \%$ of corporations achieve a growth outcome versus only $0.03 \%$ of noncorporations. ${ }^{13}$ Delaware jurisdiction is equal to 1 if the firm is registered under Delaware, but has its main office in Massachusetts (all other foreign firms are dropped before analysis). Delaware jurisdiction is favorable for firms which, due to more complex operations, require more certainty in corporate law, but it is associated with extra costs and time to establish and maintain two registrations. Between 1988 and 2005, 5.8\% of the sample registers in Delaware; $74 \%$ of firms achieving a growth outcome do so.

\footnotetext{
${ }^{12}$ Previous research highlights performance differences between incorporated and unincorporated entrepreneurs (Levine and Rubinstein, 2014).

${ }^{13}$ It is important to note that the share of corporations in Massachusetts has moved dramatically after limited liability companies where introduced in 1995, from around $92 \%$ in 1994, to 36\% in 2013.
} 
We then create two additional measures based directly on the name of the firm. Drawing on the recent work of Belenzon, Chatterji, and Daley (2014) (BCD), we use the firm and founder name to establish whether the firm name is eponymous (i.e., named after one or more of the founders). Eponymy is equal to 1 if the first, middle, or last name of the top managers is part of the name of the firm itself. ${ }^{14,15} 15 \%$ of the firms in our training sample are eponymous (an incidence rate similar to BCD), though only $1.08 \%$ for whom Growth equals one. It is useful to note that, while we draw on BCD to develop the role of eponymy as a useful start-up characteristic, our hypothesis is somewhat different than BCD: we hypothesize that eponymous firms are likely to be associated with lower entrepreneurial quality. Whereas BCD evaluates whether serial entrepreneurs are more likely to invest and grow companies which they name after themselves, we focus on the cross-sectional difference between firms with broad aspirations for growth (and so likely avoid naming the firm after the founders) versus less ambitious enterprises, such as family-owned "lifestyle" businesses.

Our second measure relates to the length of the firm name. Based on our review of naming patterns of growth-oriented start-ups versus the full business registration database, a striking feature of growth-oriented firms is that the vast majority of their names are at most two words (plus perhaps one additional word to capture organizational form (e.g., "Inc.")). Companies such as Akamai or Biogen have sharp and distinctive names, whereas more traditional businesses often have long and descriptive names (e.g., "New England Commercial Realty Advisors, Inc."). We define Short Name to be equal to one if the entire firm name has

\footnotetext{
${ }^{14}$ We consider the top manager any individual with one of the following titles: President, CEO, or Manager.

${ }^{15}$ We require names be at least four characters to reduce the likelihood of making errors from short names. Our results are robust to variations of the precise calculation of eponymy (e.g., names with a higher or lower number of minimum letters).
} 
three of less words, and zero otherwise. $47 \%$ of firms within the 1988-2005 period have a short name, but the incidence rate among growth firms is more than $80 \%{ }^{16}$

We then create four measures based on how the firm name reflects the industry or sector that the firm within which the firm is operating. To do so, we take advantage of two features of the US Cluster Mapping Project (Delgado, Porter, and Stern, 2015), which categorizes industries into (a) whether that industry is primarily local (demand is primarily within the region) versus traded (demand is across regions) and (b) among traded industries, a set of 51 traded clusters of industries that share complementarities and linkages. We augment the classification scheme from the US Cluster Mapping Project with the complete list of firm names and industry classifications contained in Reference USA, a business directory containing more than 10 million firm names and industry codes for companies across the United States. Using a random sample of 1.5 million Reference USA records, we create two indices for every word ever used in a firm name. The first of these indices measures the degree of localness, and is defined as the relative incidence of that word in firm names that are in local versus non-local industries (i.e., $\rho_{i}=$ $\frac{\sum_{j=\{\text { local firms }\}} \mathbf{1}\left[w_{i} \subseteq \text { name }_{j}\right]}{\sum_{j=\{\text { non-local firms }\}} \mathbf{1}\left[w_{i} \subseteq \text { name }_{j}\right]}$ ). We then define a list of Top Local Words, defined as those words that are (a) within the top quartile of $\rho_{l}$ and (b) have an overall rate of incidence greater than $0.01 \%$ within the population of firms in local industries (see Guzman and Stern, (2015, Table S10) for the complete list). Finally, we define local to be equal to one for firms that have at least one of the Top Local Words in their name, and zero otherwise. We then undertake a similar exercise for the degree to which a firm name is associated with a traded name. It is

\footnotetext{
${ }^{16}$ We have also investigated a number of other variants (allowing more or less words, evaluating whether the name is "distinctive" (in the sense of being both non-eponymous and also not an English word). While these are promising areas for future research, we found that the three-word binary variable provides a useful measure for distinguishing entrepreneurial quality.
} 
important to note that there are firms which we cannot associate either with traded or local and thus leave out as a third category. Just more than $15 \%$ of firms have local names, though only $3.7 \%$ of firms for whom growth equals one, and while $53 \%$ of firms are associated with the traded sector, $57 \%$ of firms for whom growth equals one do.

We additionally examine the type of traded cluster a firm is associated with, focusing in particular on whether the firm is in a high-technology cluster or a cluster associated with resource intensive industries. For our high technology cluster group (Traded High Technology), we draw on firm names from industries include in ten USCMP clusters: Aerospace Vehicles, Analytical Instruments, Biopharmaceuticals, Downstream Chemical, Information Technology, Medical Devices, Metalworking Technology, Plastics, Production Technology and Heavy Machinery, and Upstream Chemical. From 1988 to 2005, while only 5.6\% firms are associated with high technology, this rate increases to $20 \%$ within firms that achieve our growth outcome. For our resource intensive cluster group, we draw on firms names from fourteen USCMP clusters: Agricultural Inputs and Services, Coal Mining, Downstream Metal Products, Electric Power Generation and Transmission, Fishing and Fishing Products, Food Processing and Manufacturing, Jewelry and Precious Metals, Lighting and Electrical Equipment, Livestock Processing, Metal Mining, Nonmetal Mining, Oil and Gas Production and Transportation, Tobacco, Upstream Metal Manufacturing. While 14\% of firms are associated with resource intensive industries, the rate drops to $8 \%$ amongst growth firms.

Finally, we sought to develop measures that would link entrepreneurial quality to the quality and potential of the firm founders. Specifically, we construct two measures based on whether the individuals connected to the firm have been associated with start-up activity in the past. Repeat Entrepreneurship, equals 1 if the president, CEO, or manager of a firm is also listed 
as a president, $\mathrm{CEO}$, or manager in a deceased firm that became inactive before the current firm was registered. To guarantee we match the same individual we require an exact match on both name and address. We then interact Repeat Entrepreneurship with the High Tech cluster dummy to create High Tech. Repeat Entrepreneurship, a measure of serial entrepreneurship in high technology start-ups. ${ }^{17}$

Measures based on External Observables. We construct two measures related to start-up quality based on information in intellectual property data sources and one measure related to media presence close to birth. ${ }^{18}$

Building on prior research matching business names to intellectual property (Balasubramanian and Sivadasan, 2009; Kerr and $\mathrm{Fu}, 2008$ ), we rely on a name-matching algorithm connecting the firms in the business registration data to external data sources. Importantly, since we match only on firms located in Massachusetts, and since firms names legally must be "unique" within each state's company registrar, we are able to have a reasonable level of confidence that any "exact match" by a matching procedure has indeed matched the same firm across two databases. Our main results use "exact name matching" rather than "fuzzy matching"; in small-scale tests using a fuzzy matching approach (the Levenshtein edit distance (Levenshtein, 1965)), we found that fuzzy matching yielded a high rate of false positives due to the prevalence of similarly named but distinct firms (e.g., Capital Bank v. Capitol Bank, Pacificorp Inc v. Pacificare Inc.). ${ }^{19}$

\footnotetext{
${ }^{17}$ While we only use these two founder measures in this paper, we have explored other measures including estimating gender and ethnicity and plan to investigate these types of social and demographic variables in future work.

${ }^{8}$ While this paper only measures external observables related to intellectual property and media, our approach can be utilized to measure other externally observable characteristics that may be related to entrepreneurial quality (e.g., measures related to the quality of the founding team listed in the business registration (e.g., through LinkedIn profiles), or measures of early investments in scale (e.g., a web presence)).

${ }^{19}$ Our matching algorithm works in three steps. (1) First, we clean the firm name by: (a) expanding 8 common abbreviations (“Ctr.", "Svc.", "Co.", "Inc.", "Corp.", "Univ.”, "Dept.”, "LLC.”) in a consistent way (e.g., "Corp." to
} 
We construct two measures related to start-up quality based on intellectual property data sources from the U.S. Patent and Trademark Office. Patent is equal to 1 if a firm holds a patent application within the first year and 0 otherwise. We include patents that are filed by the firm within the first year of registration and patents that are assigned to the firm within the first year from another entity (e.g., an inventor or another firm). While only $0.6 \%$ of the firms Massachusetts have a patent application, 7.2\% of growth firms do. Our second measure, Trademark, is equal to 1 if a firm applies for a trademark within the first year of registration. While only $0.2 \%$ of firms have a trademark $3.7 \%$ of growth firms do.

Finally, we construct a measure based on the firm's presence in media outlets. Media Mentions is equal to 1 if a firm has a news story with its name in the business section of the Boston Globe, within a year of its founding date. To do so, we search for all firms names in the historical records of the Boston Globe allowing a one year window before and after the founding date and finding those that have articles on the business section. ${ }^{20}$ While we can identify an early media mention for only $0.14 \%$ of firms, this number increases to $3.6 \%$ when considering growth firms. $^{21}$

"Corporation"); (b) removing the word "the" from all names; (c) replacing "associates" for "associate"; and (d) deleting the following special characters from the name: . | " - @ organization type (e.g., Corporation, Incorporated, Limited Liability Company), (b) the firm name without the organization type, and (c) the firm name without the organization type and without spaces. Finally, we proceed to do the actual matching of data sets. First on firm name and organization type, then only on name, and finally on collapsed name. Our companion paper contains further tests on the name matching procedure and all our scripts are available in the online appendix.

${ }^{20}$ We identify articles in the business section by using the journalist name and only keeping those that often report business-related news.

${ }^{21}$ While this result might lead to some bias due to the geographic nature of the Boston Globe, the state of Massachusetts is sufficiently small that we expect high potential firms to be mentioned in the Boston Globe regardless of specific locations. Furthermore, all of our results are robust to excluding this measure. 


\section{Estimating Entrepreneurial Quality and Performance}

We undertake our analysis in several stages. First, we examine the relationship between our growth outcome and various start-up characteristics, identifying a candidate set of start-up characteristics from which to estimate entrepreneurial quality, and evaluate the performance of our estimator in an out-of-sample test. We then turn to the calculation of our two proposed indices, EQI and RECPI, implement and evaluate our key placecasting and nowcasting applications, and consider the overall performance of our estimator and indices as well as the interpretation of our results in the context of the broader literature.

We begin in Table 2 with a series of univariate logit regressions of Growth on each of our measured start-up characteristics. As mentioned earlier, these regressions (and all subsequent regressions) are conducted on a random 70\% training sample of the complete 1988-2005 dataset, reserving $30 \%$ of the $1988-2005$ data as a test sample. To facilitate the interpretation of our results, we present the results in terms of the odds-ratio coefficient and the pseudo- $\mathrm{R}^{2}$.

These univariate results are suggestive. Various simple measures directly captured from the registration record (such as whether the firm is a Corporation or registered in Delaware, or is named after the founder or using less than two words) are each highly significant and associated with a large increase in the probability that a given firm achieves a growth outcome. For example, corporations are associated with a more than $5 \mathrm{X}$ increase in the probability of growth, and those that register in Delaware are associated with more than a $40 \mathrm{X}$ increase in the probability of growth. Conversely, firms named after their founders have only a 5\% chance of a growth outcome relative to those with a non-eponymous name. Equally intriguing results are associated with measures of the degree of innovativeness and novelty of the start-up: Patent is 
associated with nearly a $60 \mathrm{X}$ increase in the probability of growth, and Trademark and Mentioned in Boston Globe are each associated with more than a 30X increase in the probability of growth. Importantly, not all candidate measures are associated with a meaningful statistical relationship: both of our founder measures are associated with much smaller and statistically insignificant effects on the probability of growth.

It is of course important to emphasize that each of these coefficients must be interpreted with care. While we are capturing start-up characteristics that are associated with growth, we are not claiming a causal relationship between the two: if a firm with low growth potential changes its legal jurisdiction to Delaware that is unlikely to have any impact on its overall growth prospects. $^{22}$ Instead, Delaware registration is an informative signal, based on the fact that external investors often prefer to invest in firms governed under Delaware law, of the ambition and potential of the start-up, as observed at the time of business registration. Reliance on a univariate measure makes inference particularly tricky: in isolation, one cannot evaluate whether any particular start-up characteristic is more or less important than others.

We therefore proceed in Table 3 to consider these effects in tandem. We begin by simply examining the impact of three measures directly observable from the business registration record: Corporation, Short Name, and Eponymous. Each are statistically and quantitatively significant: while corporations and short names are each associated with a more than $4 \mathrm{X}$

\footnotetext{
${ }^{22}$ One important concern in policy applications of this methodology, is that our measures might change incentives of firms, such that they try to "game" the result by select into high-quality measures they previously did not care about (e.g. changing its name form long to short). We note that this possibility, though real, is bounded by the incentives of the founders. For example, it is unlikely that a founder with no intention to grow would incur the significant yearly expense require to keep a registration in Delaware (which we estimate around \$1000). Similarly, firms that signal in their name being a local business (e.g. "Taqueria") are unlikely to change their names in ways that affect their ability to attract customers. Finally, we also note that any effects from "gaming" would be short-lived since, as low quality firms select into a specific measure the correlation between such measure and growth - and therefore the weight our prediction model would assign to it - weakens.
} 
increase in the probability of growth, eponymy reduces the probability of growth by nearly $95 \%$. When we introduce cluster dummies in (2), the results for these business registration measures remains similar; at the same time, the results suggest that businesses whose names are associated with a traded high technology cluster are more than $3 \mathrm{X}$ more likely to grow and local businesses register a $64 \%$ growth probability penalty. In (3), the inclusion of a dummy for whether the firm registers in Delaware has several effects. First, and most importantly, Delaware registration is associated with more than $40 \mathrm{X}$ increase in the probability of growth (we once again caution that this effect is not causal but instead helps identify firms whose underlying potential both makes them more likely to register in Delaware and more likely to realize a growth outcome). At the same time, the inclusion of the Delaware dummy reduces the measured penalty associated with eponymy and being associated with a local business name, and reduces the boost associated with being in a high technology cluster. Interestingly, the pseudo- $\mathrm{R}^{2}$ increases from $11 \%$ to $31 \%$ with the inclusion of the Delaware dummy. The specification in (3) is particularly interesting since these data rely only on information directly observable from the registration record, and so in principle can be observed on a nearly real-time basis for the purposes of a nowcasting version of EQI.

In (4), we move towards incorporating measures that capture key early milestone achievements for a start-up that might serve as informative signals for their likelihood of entrepreneurial success. Events such as the assignment of a patent, a patent or trademark application, or mention in the media can only occur once the venture has been launched, but might occur in a timely enough manner to still provide information for the purposes of entrepreneurial quality estimation (particularly for EQI applications in which we would like to examine particular regions and places on an historical basis). Model 4 includes two measures of 
intellectual property. Since the patent and Delaware indicators are highly correlated $(62 \%$ of patenting firms are also registered in Delaware), we separate the effect into distinct interaction components. Having a patent increases the likelihood of growth 40 times, and Delaware firms are 40 times more likely to achieve growth. Interestingly, the combined effect (131.9) is smaller than the joint product of the individual effects. Finally, a firm with an early trademark is more than 3 times more likely to grow. Importantly, the business registration coefficients remain similar in magnitude and statistical significance to the results in (3). Model 5 includes one additional measure, Mentioned in Boston Globe, which captures whether the start-up was mentioned in the business section of the primary Massachusetts newspaper within the first year after registration. Media is associated with more than a $5 \mathrm{X}$ increase in the probability of growth, and the coefficients associated with the other variables remains similar.

Finally, (6) and (7) include two measures to capture the impact of serial entrepreneurship - one based on whether at least one of the founders has ever been associated with a Massachusetts start-up before and the other interacting that measure with our high-technology cluster variable. Though the direction of each of these measures is as predicted, neither is significant nor large (relative to many of the other coefficients in these regressions). We should emphasize that, since we require that the serial entrepreneur maintains their address between the two ventures, we may be not yet capturing and tracking serial entrepreneurship in a meaningful way. Identifying more precise and nuanced information from founders is an important agenda for future research using this methodology.

Overall, these regressions offer striking indicators of the relationship between observable start-up characteristics and the realization of growth. There is dramatic variation in the estimated probability of growth for individual firms. For example, using the estimates from (5), comparing 
the growth probability of a Delaware corporation with a patent and trademark $(116.3 * 3.4 * 7.9)$ to a Massachusetts LLC without intellectual property yields an odds-ratio of $3097: 1 .^{23}$ Importantly, the overall results accord well with Guzman and Stern (2015), which uses the same methodology on California data: if supported by further evidence from other states and jurisdictions going forward, the stable nature of the markers of entrepreneurial quality provide an important foundation for the creation of robust economic statistics in this area.

Candidate Specification Choice and Evaluation. Before turning to the calculation of our indices and exploration of our nowcasting and placecasting applications, we first investigate whether it is possible to identify a preferred benchmark candidate specification that we can use as our basis for entrepreneurial quality estimation going forward. To do so, we first compare models that include or exclude specific sets of regressors using a standard likelihood ratio test. Specifically, in each row of Table 4, we compare the likelihood function (as well as differences in pseudo- $\mathrm{R}^{2}$ (McFadden, 1974)) between two models, one of which (M) is nested in the other (N). For the first five rows (where we introduce different combinations of restricted and unrestricted specifications), we can reject the null hypothesis associated with the restricted model. In other words, regardless of which variables we include first, we find significant explanatory effects from the Media, IP, and full range of Business Registration measures. However, regardless of specification, we find no robust effects associated with our founder measures. As such, for the remainder of our analysis, we adopt (3-5) as our preferred specification in evaluating our estimator.

\footnotetext{
${ }^{23}$ More dramatically, at the (near) extreme, comparing the growth probability of a Delaware corporation with a patent (7.8 * 116.3), trademark (3.4), media mention (5.7) and non-eponymous short name (6.9* 2.4) with an eponymous partnership or LLC with a long name but no intellectual property or media mentions, the odds-ratio is 295,115 to one!
} 
We then evaluate our estimates using the $30 \%$ test sample of observations which have not been used in the estimation but for which we observe both the growth outcome and start-up characteristics. In particular, using only data from the test sample (but relying on the estimates from (3-5) to estimate entrepreneurial quality), Figure 1 presents the relationship between the distribution of realized growth events versus the distribution of firm-level entrepreneurial quality. The results are striking. $77 \%$ of all growth firms are in the top $5 \%$ of our estimated growth probability distribution, and $49 \%$ are within the top $1 \%$ (interestingly, these results are extremely similar to the findings for California from Guzman and Stern (2015)). To be clear, growth is still a relatively rare event even among the elite: the average firm within the top $1 \%$ of estimated entrepreneurial quality has only a $14 \%$ chance of realizing a growth outcome.

As well, we evaluate whether our results are driven by the particular sample which was drawn for the training sample. This is particularly relevant as growth is rare in our dataset (only 462 , or $0.14 \%$ ) and several of our measures are also relatively rare (e.g., less than one per cent of all firms patent or receive a trademark). To evaluate whether our sampling matters, we repeat the process of separating out the sample into a training and test sample 100 times, implement (35) with each draw to estimate entrepreneurial quality for each firm in that draw's test sample, and then calculate a test statistic which is equal to the number of realized growth outcomes in the test sample which we estimate to be in the top $5 \%$ of the estimated quality distribution. Relative to our baseline sample result of $77 \%$, the mean of this test statistic is $79 \%$ (with a $95 \%$ confidence interval between $73 \%$ and $84 \%$ ). At least within the overall Massachusetts sample in this paper, our estimates of entrepreneurial quality are robust to the sample that we draw.

\section{Calculating Entrepreneurial Quality and Performance Indices}


We now turn to the centerpiece of our analysis: the calculation of EQI and RECPI at different levels of geographic agglomeration and across time in order to evaluate a number of different placecasting and nowcasting applications. We now incorporate the full sample of Massachusetts firms from 1988 through 2012, and so include the part of the prediction sample for which we can observe the full set of start-up characteristics (recall that our baseline candidate (3-5) involves a two-year lag between founding date and the incorporation of early patenting, trademark, and media data).

We begin with the calculation of RECPI for the state of Massachusetts for each year between 1988 and 2012. In Figures 2(A) and 2(B), we compare the realized level of growth events (per start-up cohort) with two different entrepreneurship indices: a simple measure of entrepreneurial quantity (the number of newly registered businesses for that cohort) versus RECPI which scales the number of registered businesses by the EQI for those businesses for each cohort year. While there appears to be no correlation between the realized growth events from a cohort and entrepreneurial quantity, there is a much closer relationship with RECPI, where we are incorporating entrepreneurial quality. RECPI grows at a rapid rate from 19912000 (with a very large spike in 1999-2000) and then falls dramatically (along with the realized level of exits between 2001-2004). From 2004-2012, Massachusetts RECPI has increased by approximately $17 \%$. Intriguingly, as we discuss in the Conclusion (and consistent with the emphasis on investment cycles and start-up dynamics by Nanda and Rhodes-Kropf (2013)), the notable divergence between realized growth events and RECPI is coincident with the rapid rise and collapse of the early-stage risk capital market in the late 1990s: realized growth events were much "higher" than predicted for the 1995-1998 cohorts, essentially on-target for the 1999 cohort, and much lower for all subsequent cohorts. 


\section{Placecasting Entrepeneurial Quality}

We now turn to a set of placecasting applications where we calculate EQI and RECPI for different regions in Massachusetts (and during different time periods); in order to illustrate the range of potential applications with these tools, we begin at a relatively aggregate level of geographic scope and then focus in on much more granular analyses (i.e., we move from the state to the city to the neighborhood to the individual address level). We begin in Figure 3 where we calculate EQI for all firms registered in each of 351 distinct municipalities in Massachusetts from 2007-2012. Though this map completely abstracts away from quantity (EQI is simply the average quality for each town), there is a striking concentration of quality around the Boston metropolitan area. Relative to an average EQI for the state of 0.8 , Cambridge records the highest level of average quality at 5.7 (i.e., the average firm founded in Cambridge has a 5 in 1000 chance in realizing growth which is nearly 8 times higher than an average firm in Massachusetts). Cambridge is followed by a cluster of cities around the north-west section between the Route 128 and 495 corridors, including Bedford, Waltham, Burlington, Lexington, and Woburn. Maynard (the founding town for DEC Computers) ranks seventh with an EQI of 3.4. Though by far the largest city in Massachusetts (and the clear leader in the total number of business registrations), Boston ranks $23^{\text {rd }}$ in the state with an EQI of 2.0 between 2007-2012. Though quality is highly concentrated around Boston, there are clusters of entrepreneurial quality around different parts of the Commonwealth, including Amherst, Foxborough, and Beverly. Importantly, quality is in the bottom half of the distribution in several former industrial cities, including Worcester. Finally, quality is consistently low in popular vacation destinations such as Cape Cod, Martha's Vineyard, and the Berkshires. 
These overall patterns of concentrated quality hold more generally over time. In Figure 4, we calculate EQI for the five largest counties in Massachusetts (associated with more than 95\% of all growth outcomes) between 1988 and 2012. Over the past twenty-five years, Middlesex County (which includes both Cambridge and many of the key Route 128 towns) has held a distinctive advantage in EQI, with a more recent period of convergence with Suffolk County (i.e., Boston). Within this broad pattern, there are striking dynamics among entrepreneurial clusters within Boston. In Figure 5, we plot RECPI for three distinct areas: the Route 128 Corridor (which we define as Waltham, Burlington, Lexington, Lincoln, Concord, Acton and Wellesley), Cambridge, and Boston. During the 1990s, Route 128 contained the highest level of RECPI, even though the combined populations of the Route 128 cities are only $29 \%$ of the total population of Boston. Over the past decade, there has been a dramatic shift in overall entrepreneurial leadership in the Boston area. Cambridge now outpaces both Boston and the Route 128 corridor, though both Boston and Cambridge experienced a significant estimated increase in RECPI between 2009 and 2012. These changes are consistent with more qualitative accounts: a range of media and academic commentators have highlighted the rise of Cambridge as a hub of high-growth entrepreneurship (Katz and Wagner, 2014), and our estimates provide direct evidence for this phenomena and also suggest that this rise is not simply the result of a localized expansion of risk capital but instead reflects an increase in the intrinsic quality of startups within Cambridge relative to more suburban locations.

We further enhance the granularity of our analysis in Figure 6, where we calculate EQI for each zip code in the Boston metropolitan area for the 2007-2012 period. Here we can see that, even within cities such as Cambridge or Boston, there is considerable heterogeneity: Kendall Square (02142) register the single highest level of EQI in the state, followed by the zip 
code associated with the Harvard Business School (02163). Other notable areas of entrepreneurial quality include the area surrounding the Boston Innovation District (02210) as well as a set of zip codes along the Route 128 corridor surrounding Lincoln Laboratories, as well as the remaining zip codes within Cambridge. Wealthy residential districts such as Newton, Brookline and Weston are associated with lower levels of average entrepreneurial quality.

Looking over time at a comparison between MIT/Kendall Square (02142), the area surrounding Harvard University (02138 and 02163) and the Boston Seaport area (which now includes the Boston Innovation District) (02210), we see that each of these areas registered a similar level of entrepreneurial quality in the late 1980s and early 1990s. However, beginning around 1994, the MIT/Kendall Square area began to experience a significant and sustained rise in average entrepreneurial quality, and (contra the overall pattern of risk capital financing) actually reached its highest level (in terms of an average) in 2003. The average for the MIT/Kendall Square area again increased over the second half of the last decade, and experienced a very sharp increase in 2011 and 2012. A higher level of stability is observed in the Harvard and Seaport District, though the Seaport District registers a significant rise starting in 2010, coincident with the establishment of the Boston Innovation District in this area by Mayor Thomas Menino. While the rise of the MIT/Kendall Square area has been much discussed (Katz and Wagner, 2010), it is nonetheless striking to see the impact of this sustained pattern of economic on the geography of entrepreneurial quality.

We further refine our analysis and illustrate the potential of our approach by examining the micro-geography of entrepreneurial quality at the level of individual addresses. Figure 8 shows the complete set of new business registrants between 2008-2012 in the three zip codes adjacent to MIT: 02139, 02141, and 02142. For each address where at least one start-up 
registers, we include a circle whose radius is proportional to the number of business registrants, and whose color is determined by the average level of entrepreneurial quality at that location. The results are striking, with a very significant level of variation across individual addresses. Across these two square miles, the average level of entrepreneurial quality (weighted by address) is 6.0 but the median is 0.1 , reflecting a highly skewed distribution. On the one hand, the area around Central Square and Cambridgeport (to the north and west of MIT) are characterized by a large number of addresses with a very small number of start-up events, each of which is estimated to have a low level of quality (with EQI registering at 0.1 and lower for the majority of individual addresses). While there are some addresses in Central Square and Cambridgeport registering significant levels of entrepreneurial quality (particularly along Massachusetts Avenue), these are dwarfed by the intensive concentration of entrepreneurial quality (both in terms of EQI and RECPI at each location) that immediately surrounds the Kendall Square area (to the east of MIT). One Broadway, the home of the Cambridge Innovation Center, is the home to 229 business registrants, with an average entrepreneurial quality score of 15 . The Atheneum (215 $1^{\text {st }}$ Street, a space that includes dedicated wet lab space for life sciences companies) hosted 15 firms with an average entrepreneurial quality score of more than 70 . While entrepreneurship is distributed across the MIT ecosystem, the cluster of world-class entrepreneurial quality surrounding MIT is concentrated in an even smaller geographic area.

\section{Nowcasting Entrepeneurial Quality}

While our placecasting applications offer significant insight into the geography or entrepreneurial quality and change in entrepreneurial quality over longer time periods, the development of a measurement approach for entrepreneurial quality for policymakers must be able to be calculated in a timely manner in order for it to be relevant and useful for policy 
decisionmaking. Indeed, a contribution of our method is the ability to predict entrepreneurial quality for recent start-up cohorts (that have not yet realized growth outcomes or not) based on observable start-up characteristics. However, in our discussion of an estimation model in Section V, we prioritized the inclusion of start-up characteristics that allow us to differentiate between start-ups in nuanced ways rather than prioritizing the timeliness and ease of calculating entrepreneurial quality. Most notably, our key measures associated with intellectual property (either patents or trademarks) as well as our measure of media mentions are only observed with a lag. For example, in the case of patents, inclusion of a measure of whether a firm files a patent within one year after business registration necessitates a 2.5 year lag between business registration and the inclusion of that firm in an entrepreneurial quality estimate (since patent applications are not disclosed until 18 months after filing). Alternatively, one could prioritize being able to calculate a perhaps more noisy estimate of entrepreneurial quality with real-time data that could be directly estimated from data available within the business registration record itself. In Figure 9, we compare the patterns of indices that are based on EQI estimates that depends only on information directly observable from business registration records (i.e., based on (3-3)) with our baseline index that allows for a two-year lag that allows the estimate of entrepreneurial quality to incorporate early milestones such as patent or trademark application or being featured in local newspapers (i.e., (3-5)). In Figure 9(A), we simply compare the overall RECPI for Massachusetts based on our baseline index versus an index that is explicitly prioritizes nowcasting. The results are intriguing: there is a very close relationship between the two through 2000, and, while there is divergence over time, the correlation between the two 
indices is very high through the end of 2012. Interestingly, Massachusetts continues to register an improving level of RECPI in 2013 and through November 24, $2014 .^{24}$

We then turn in Figures B and $\mathrm{C}$ to evaluate how our more granular analyses fare when comparing the baseline and nowcasting indices. In Figure 9(B), we revisit the comparison between Route 128, Cambridge and Boston. On the one hand, nowcasting advantages Boston over these two other areas in terms of an overall ranking (presumably because Cambridge and Route 128 are associated with firms that are more focused on formal intellectual property). At the same time, beyond this level effect for Boston, the historical patterns are quite similar, with a clear transition of entrepreneurial leadership from Route 128 to Cambridge over time. Indeed, this gap sees to have only increased in the last two years. Finally, Figure $9(\mathrm{C})$ compares three neighborhood clusters: MIT/Kendall Square, Harvard, and the Boston Innovation District. As in Figure 9(B), the overall historical patterns are similar, though the absolute size of the gap between the MIT area and the others is smaller. From a nowcasting perspective, the use of more recent data documents the rise of the Boston Innovation District in a more sustained way, and only suggests that the rate of new firm formation may have slowed after a dramatic rise between 2010 and 2011 (presumably because the initial firms within the District created an bump during 2011).

Evaluating Entrepreneurial Quality and Performance.

As a final exercise, we examine how our proposed measures perform in terms of predicting the number of realized growth events associated with a given regional cohort. In Table 5, we perform a series of regressions in which the dependent variable is the number of

\footnotetext{
${ }^{24}$ For the sake of comparison, we scale the measure for 2014 by estimating the number of firms that will register from November 24 to December 31 in 2014 through an adjustment equivalent to the share of firms that were registered over these dates in 2013 (i.e., we multiply our estimate by 1.09).
} 
Growth events per county-year, and examine various measures of entrepreneurship (and include county fixed effects to account for differences in county overall size and composition). In (5-1), we simply examine a measure of quantity $(\ln (\#$ of births $))$ : the coefficient is small, noisy, and negative. In (5-2), we employ churn, a standard measure of business dynamism (Haltiwanger, et al) to examine the impact of this measure on the number of growth events within a conty. Though positive, the coefficient is small and remains insignificant. Even taken at face value, the effect would be modest: doubling the level of churn would be associated with just an $8 \%$ increase in the total number of expected growth events. Turning to EQI, we find a far more encouraging result: EQI is not only statistically significant but also associated with a meaningful increase in the realized number of growth events. Finally, RECPI is associated with a very large increase in the overall elasticity: doubling RECPI is associated with more than a $50 \%$ increase in the number of expected growth events in a region-cohort-year. Though we caution that we need to investigate this result further, it points to an important potential additional lens through which to utilize these tools: an important share of realized growth events are due to "intrinsic" factors observable at the time of founding, with other factors such as regional ecosystems, timing, and idiosyncratic factors playing separate roles. The variance decomposition of entrepreneurial growth remains an important topic for future research.

\section{Conclusion}

Motivated by the need to account directly for heterogeneity among entrepreneurial ventures, this paper has developed and applied a methodology that allows for the estimation of entrepreneurial quality that facilitates both placecasting (identifying clusters of entrepreneurial quality without direct use of location information in the prediction) and nowcasating (forecasting 
the realized entrepreneurial quality of recent cohorts based on start-up characteristics but in advance of realizing growth outcomes). We specifically introduce very preliminary exemplars for two new economic statistics - an entrepreneurial quality index (EQI) and a regional entrepreneurship cohort potential index (RECPI). While we emphasize that our approach is still preliminary, we believe that the more general methodology offered here has the potential for application by policymakers and analysts. Given the possibility that entrepreneurial quality is a leading indicator for other outcomes in regional performance, tracking EQI would allow government analysts to measure and manage entrepreneurial quality, and so track entrepreneurial dynamics in a more proactive and informed way. Not simply a tool for direct measurement, our methodology further allows government organizations (e.g., the Small Business Administration) to design and evaluate interventions that focus on the quality of entrepreneurship rather than only increasing rates of firm formation, thus facilitating an approach that could potentially increase the impact of such interventions substantially.

While our focus in this paper has been in the development and preliminary application of our methodology to address key challenges in the measurement of entrepreneurship, our results also highlight potential linkages with areas of theoretical or policy interest. For example, RECPI, our quantity-adjusted index, estimates the expected number of growth events from a cohort given its start-up characteristics, without accounting for regional effects or financial cycles. Thus, RECPI can be interpreted as the "potential" of a cohort of new firms given their intrinsic qualities. In close interplay with recent theory that relates changes in the demand for quality entrepreneurship to investment cycles dynamics (Nanda and Rhodes-Kropf, 2013), our index documents substantial year to year changes in the supply of quality of entrepreneurship. The relationship is pro-cyclical - cohorts increase in quality as the investment opportunities 
improve and the market gets "hotter". However, the realized performance of a cohort is affected by two opposing effects from the investment cycle: while later cohorts in the cycle have more intrinsic potential to generate growth, earlier cohorts have more time in the "hot" market (before a recession like the dot-com bust) to achieve it. The changing time dynamics of the supply of entrepreneurial quality and its interplay with regional outcomes is an open area of research.

Spatially, in similarity to previous results that find substantial agglomeration of innovation relative to overall industrial activity (Furman, Porter, and Stern,2002; Audretsch and Feldman, 1996), we find entrepreneurial quality is substantially more concentrated than entrepreneurial quantity or population. While there are several potential reasons for this pattern, we find no reason to conclude any a-priori, and thus suggest this as an interesting finding with potential for future research.

Finally, our results highlight the micro-geography of the quality of entrepreneurship and suggest that clusters of entrepreneurial quality may benefit from being analyzed at a very low level of aggregation. In the spirit of recent work emphasizing the highly local nature of knowledge spillovers and the nuanced shapes of entrepreneurial clusters (Arzhagi and Henderson, 2008; Kerr and Kominers, 2015), examining the factors that shape the boundaries of high-quality entrepreneurship is an important area for future research. 


\section{References}

Aghion, Philippe and Peter Howitt. (1992) “A Model of Growth Through Creative Destruction” Econometrica, 60(2): 323-351.

Amoros, Jose E., and Neils Bosma. (2014) “Global Entrepreneurship Monitor: 2013 Executive Report” London, GB: London Business School, and Wellesley, MA: Babson College.

Arzaghi, Mohammad, and J. Vernon Henderson. (2008) "Networking of Madison Avenue" Review of Economic Studies. 75 (4): 1011-1038

Audretsch, David B \& Maryann P. Feldman. (1996) "R\&D Spillovers and the Geography of Innovation and Production," American Economic Review. 86(3): 630-640.

Balasubramanian, Natarajan, and Jagadeesh Sivadasan. (2009) "NBER Patent Data-BR Bridge: User Guide and Technical Documentation”. Working Paper.

Barnes, Beau, Harp, Nancy, Oler, Derek. (2014) "Evaluating the SDC Mergers and Acquisitions Database" SSRN Working Paper \#2201743

Belenzon, Sharon, Chatterji, Aaron and Brendan Daley. (2014) "Eponymous Entrepreneurs" Working Paper

Carlino, Geraldo, Catterjee, Satyajit, and Robert Hunt. (2007) “Urban Density and the Rate of Invention”. Journal of Urban Economics. 61 (3): 389-419

Davis, Steven, and John Haltiwanger. (1992) "Gross Job Creation, Gross Job Destruction, and Employment Reallocation”. The Quarterly Journal of Economics. 107 (3): 819-862

Decker, Ryan, Haltiwanger, John, Jarmin, Ron and Javier Miranda. (2014) “The Role of Entrepreneurship in US Job Creation and Economic Dynamism”. Journal of Economic Perspectives. 28(3): 3-24`

Delgado, Mercedes, Porter, Michael, and Scott Stern. (2015) “Defining Clusters in Related Industries.” Journal of Economic Geography. forthcoming

Fairlie, Robert W.. (2014) "Kaufman Index of Entrepreneurial Activity: 1996-2013." Ewing Marion Kaufman Foundation, Kansas City, MS.

Feldman, Maryann, and David Audrestch. (1999) "Innovation in cities: Science-based diversity, specialization and localized competition". European Economic Review. 43(2): 409-429.

Furman, Jeffrey, Porter, Michael and Scott Stern. (2002) "The determinants of national innovative capacity". Research Policy. 31:899-933

Graham, Stuart, Hancock, Galen, Marco, Alan, and Amanda Fila Myers. The USPTO Case Files Dataset: Descriptions, Lessons and Insights. United States Patent and Trademark Office. SSRN Working Paper \#2188621 (2013)

Gompers, Paul, Kovner, Anna, Lerner, Josh, and David Scharfstein. (2010) "Performance Persistence in Entrepreneurship." Journal of Financial Economics. 96(1): 18-32.

Guzman, Jorge, and Scott Stern. (2015) “Where is Silicon Valley?” Science. Vol. 347. Issue \#6222. 
Hamilton, Barton. (2000) "Does Entrepreneurship Pay? An Empirical Analysis on the Returns to SelfEmployment”. Journal of Political Economy. 108(3): 604-631.

Hastie, Trevor, Tibshirani, Robert, and John Friedman. (2001) “The Elements of Statistical Learning”. Second Edition. Springer.

Hurst, Erik, and Benjamin Pugsley. (2011) "What do Small Businesses Do?”. Brookings Papers on Economic Activity.

Jaffe, Adam, Trajtenberg, Manuel, and Rebecca Henderson. (1993) "Geographic Localization of Knowledge Spillovers as Evidenced by Patent Citations.” Quarterly Journal of Economics. 108 (3): 577-598.

Jovanovic, Boyan. (1982) "Selection and the Evolution of Industry." Econometrica. 50(3): 649-670.

Katz, Bruce, and Julie Wagner. (2014) "The Rise of Innovation Districts: A New Geography of Innovation in America". Brookings Institution - Metropolitan Policy Program.

Kerr, William, Nanda, Ramana, and Matthew Rhodes-Kropf. (2014) "Entrepreneurship as Experimentation". Journal of Economic Perspectives. 28 (3): $\quad$ 25-48.

Kerr, William, and Shihe Fu. (2008) "The Survey of Industrial R\&D--Patent Database Link Project." Journal of Technology Transfer. 33 (2):173-186

Kerr, William, and Scott Kominers. (2015) Review of Economics and Statistics. forthcoming

Klapper, Leora, Amit, Raphael, Guillen, Mauro. (2010) "Entrepreneurship and Firm Formation across Countries". NBER Volume: International Differences in Entrepreneurship. Edited by Josh Lerner and Antoinette Schoar.

Kuznets, Simon. (1941) “National Income and its Composition, 1919-1938. Volume I” p. 3.

Lafontaine, Francine, and Kathryn Shaw. (2014) "Serial Entrepreneurship: Learning by Doing?" NBER Working Paper \#20312

Levenshtein, V. I. (1965), "Binary codes capable of correcting deletions, insertions, and reversals.", Doklady Akademii Nauk SSSR 163 (4): 845-848

Levine, Ross, and Yona Rubinstein. (2013) "Smart and Illicit: Who Becomes an Entrepreneur and Does it Pay?" NBER Working Paper \#19276

Hathaway, Ian, and Robert Litan. (2014) "Declining Business Dynamism in the United States: A Look at States and Metros". Economic Studies at Brookings. Brookings Institution.

Hathaway, Ian, and Robert Litan. (2014) “Declining Business Dynamism: It's For Real” Comment.

McFadden, Daniel. (1974) "Conditional logit analysis of qualitative choice behavior". Frontiers in Econometrics. Chapter 4. Academic Press. p. 105-142.

Moskowitz, T., \& Vissing-Jorgensen, A. (2002). "The Returns to Entrepreneurial Investment: A Private Equity Premium Puzzle?" American Economic Review. 92(4): 745-778.

Nanda, Ramana, and Matthew Rhodes-Kropf. (2014) “Financing Risk and Innovation”. HBS Working Paper 11013. 
Nanda, Ramana, and Matthew Rhodes-Kropf. (2013) "Investment Cycles and Startup Innovation." Journal of Financial Economics (110): 403-418.

Pohlman, John, and Dennis Leitner. (2003) "A Comparison of Ordinary Least Squares and Logistic Regression.” The Ohio Journal of Science. 103 (5): 118-125

Reister, Shane. (2014) "Why Should we Actively Track and Measure Startup Communities." Available in: Kauffman Thoughtbook 2015 - Entrepreneurship: New Directions for a New Era. Retrieved from: http://www.kauffman.org/thoughtbook2015/paths-to-entrepreneurship\#startupcommunities on December, 2014.

Schumpeter, Joseph A. (1942) “Capitalism, Socialism, and Democracy”. New York: Harper.

Schoar, Antoinette. (2010) "The Divide Between Subsistence and Transformational Entrepreneurship". Innovation Policy and the Economy, Volume 10. Edited by Josh Lerner and Scott Stern.

Taddy, Mathew. (2013) "Big Data Analysis". Lecture on NBER Summer Institute: Econometric Methods for HighDimensional Data. 
TABLE 1. Summary Statistics for Massachusetts Firms*

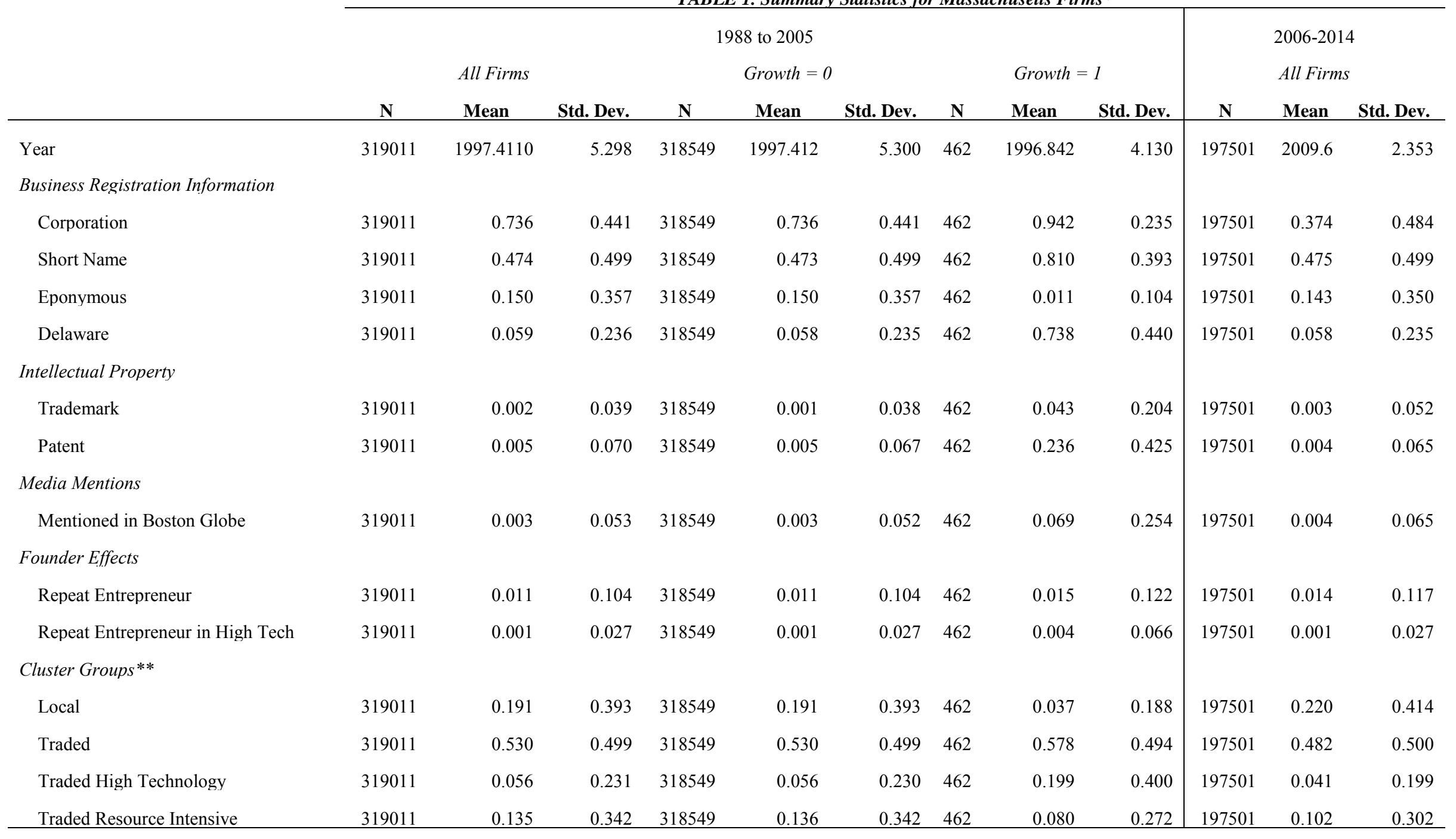

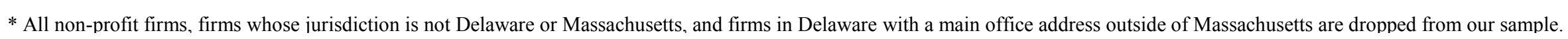

** Cluster groups are calculated grouping industry clusters in the US Cluster Mapping Project into five large categories. 
TABLE 2. Univariate Logit from Predictors on Growth

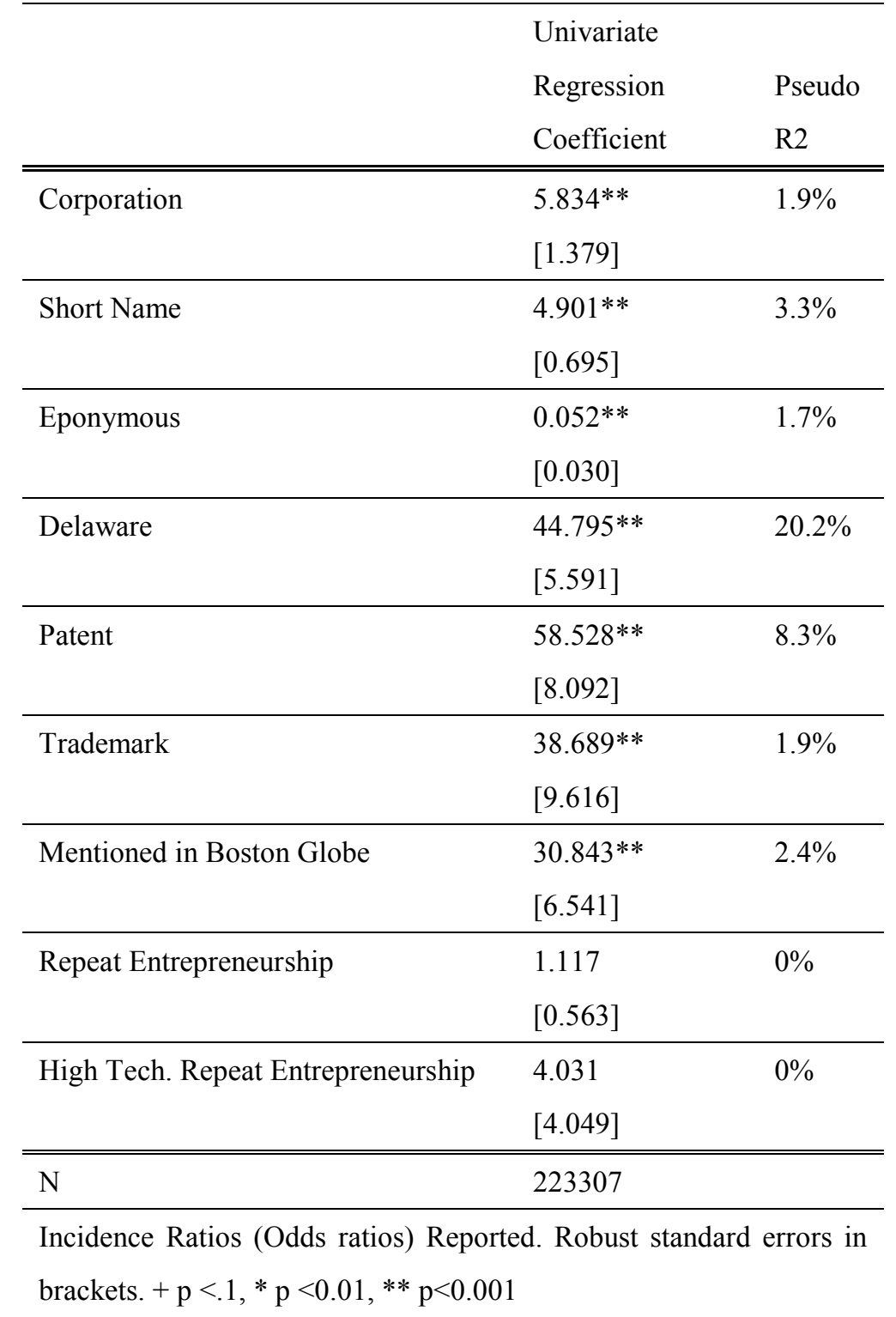


TABLE 3. Logit Regression on Growth (IPO or Acquisition in 6 years or less)

\begin{tabular}{|c|c|c|c|c|c|c|c|}
\hline & \multicolumn{3}{|c|}{ Firm Business Registration Data } & \multicolumn{2}{|c|}{$\underline{\text { Lagged Measures }}$} & \multicolumn{2}{|c|}{ Other Measures } \\
\hline & 1 & 2 & 3 & 4 & 5 & 6 & 7 \\
\hline Corporation & $\begin{array}{l}5.471 * * \\
{[1.288]}\end{array}$ & $\begin{array}{l}5.155^{* *} \\
{[1.222]}\end{array}$ & $\begin{array}{l}8.863 * * \\
{[2.174]}\end{array}$ & $\begin{array}{l}8.065 * * \\
{[1.994]}\end{array}$ & $\begin{array}{l}7.872 * * \\
{[1.948]}\end{array}$ & $\begin{array}{l}7.880 * * \\
{[1.952]}\end{array}$ & $\begin{array}{l}7.885 * * \\
{[1.953]}\end{array}$ \\
\hline Short Name & $\begin{array}{l}4.207 * * \\
{[0.595]}\end{array}$ & $\begin{array}{l}3.840 * * \\
{[0.539]}\end{array}$ & $\begin{array}{l}2.693 * * \\
{[0.393]}\end{array}$ & $\begin{array}{l}2.454 * * \\
{[0.365]}\end{array}$ & $\begin{array}{l}2.373 * * \\
{[0.355]}\end{array}$ & $\begin{array}{l}2.372 * * \\
{[0.355]}\end{array}$ & $\begin{array}{l}2.372 * * \\
{[0.355]}\end{array}$ \\
\hline Eponymous & $\begin{array}{l}0.0568 * * \\
{[0.0330]}\end{array}$ & $\begin{array}{l}0.0639 * * \\
{[0.0371]}\end{array}$ & $\begin{array}{l}0.132 * * \\
{[0.0776]}\end{array}$ & $\begin{array}{l}0.145 * \\
{[0.0850]}\end{array}$ & $\begin{array}{l}0.143 * * \\
{[0.0826]}\end{array}$ & $\begin{array}{l}0.143 * * \\
{[0.0826]}\end{array}$ & $\begin{array}{l}0.143 * * \\
{[0.0826]}\end{array}$ \\
\hline Delaware & & & $\begin{array}{l}42.63 * * \\
{[5.876]}\end{array}$ & & & & \\
\hline \multicolumn{8}{|l|}{ Delaware Patent Interactions } \\
\hline Patent Only & & & & $\begin{array}{l}40.36 * * \\
{[13.48]}\end{array}$ & $\begin{array}{l}39.98 * * \\
{[13.26]}\end{array}$ & $\begin{array}{l}40.00 * * \\
{[13.26]}\end{array}$ & $\begin{array}{l}40.00 * * \\
{[13.26]}\end{array}$ \\
\hline Delaware Only & & & & $\begin{array}{l}40.38 * * \\
{[6.100]}\end{array}$ & $\begin{array}{l}38.33 * * \\
{[5.864]}\end{array}$ & $\begin{array}{l}38.33 * * \\
{[5.861]}\end{array}$ & $\begin{array}{l}38.33 * * \\
{[5.860]}\end{array}$ \\
\hline Patent and Delaware & & & & $\begin{array}{l}131.9 * * \\
{[26.20]}\end{array}$ & $\begin{array}{l}116.3 * * \\
{[23.84]}\end{array}$ & $\begin{array}{l}116.2 * * \\
{[23.80]}\end{array}$ & $\begin{array}{l}116.3 * * \\
{[23.79]}\end{array}$ \\
\hline Trademark & & & & $\begin{array}{l}3.369 * * \\
{[0.990]}\end{array}$ & $\begin{array}{l}3.383 * * \\
{[1.005]}\end{array}$ & $\begin{array}{l}3.382 * * \\
{[1.004]}\end{array}$ & $\begin{array}{l}3.386 * * \\
{[1.006]}\end{array}$ \\
\hline Mentioned in Boston Globe & & & & & $\begin{array}{l}5.742 * * \\
{[1.518]}\end{array}$ & $\begin{array}{l}5.747 * * \\
{[1.516]}\end{array}$ & $\begin{array}{l}5.738 * * \\
{[1.508]}\end{array}$ \\
\hline \multicolumn{8}{|l|}{ Founder Effects } \\
\hline Repeat Entrepreneurship & & & & & & $\begin{array}{l}0.931 \\
{[0.507]}\end{array}$ & $\begin{array}{l}0.855 \\
{[0.533]}\end{array}$ \\
\hline High Tech. Repeat Entrepreneurship & & & & & & & $\begin{array}{l}1.496 \\
{[1.972]}\end{array}$ \\
\hline \multicolumn{8}{|l|}{ US Cluster Mapping Groups } \\
\hline Local & & $\begin{array}{l}0.323 * * \\
{[0.0884]}\end{array}$ & $\begin{array}{l}0.636 \\
{[0.181]}\end{array}$ & $\begin{array}{l}0.718 \\
{[0.206]}\end{array}$ & $\begin{array}{l}0.726 \\
{[0.209]}\end{array}$ & $\begin{array}{l}0.726 \\
{[0.209]}\end{array}$ & $\begin{array}{l}0.726 \\
{[0.209]}\end{array}$ \\
\hline Traded & & $\begin{array}{l}1.119 \\
{[0.145]}\end{array}$ & $\begin{array}{l}1.033 \\
{[0.137]}\end{array}$ & $\begin{array}{l}1.115 \\
{[0.150]}\end{array}$ & $\begin{array}{l}1.133 \\
{[0.154]}\end{array}$ & $\begin{array}{l}1.134 \\
{[0.153]}\end{array}$ & $\begin{array}{l}1.134 \\
{[0.154]}\end{array}$ \\
\hline Traded Resource Intensive & & $\begin{array}{l}0.415^{* *} \\
{[0.0863]}\end{array}$ & $\begin{array}{l}0.642+ \\
{[0.135]}\end{array}$ & $\begin{array}{c}0.655+ \\
{[0.137]}\end{array}$ & $\begin{array}{l}0.640+ \\
{[0.133]}\end{array}$ & $\begin{array}{l}0.640+ \\
{[0.133]}\end{array}$ & $\begin{array}{l}0.638+ \\
{[0.134]}\end{array}$ \\
\hline Traded High Technology & & $\begin{array}{l}3.971 * * \\
{[0.606]}\end{array}$ & $\begin{array}{l}2.197 * * \\
{[0.349]}\end{array}$ & $\begin{array}{l}1.748 * * \\
{[0.286]}\end{array}$ & $\begin{array}{l}1.783 * * \\
{[0.293]}\end{array}$ & $\begin{array}{l}1.782 * * \\
{[0.293]}\end{array}$ & $\begin{array}{l}1.773 * * \\
{[0.292]}\end{array}$ \\
\hline Observations & 223307 & 223307 & 223307 & 223307 & 223307 & 223307 & 223307 \\
\hline Pseudo R-squared & 0.064 & 0.090 & 0.277 & 0.302 & 0.310 & 0.310 & 0.310 \\
\hline Log-Likelihood & -2320.6 & -2258.1 & -1792.7 & -1731.7 & -1712.1 & -1712.1 & -1712.0 \\
\hline
\end{tabular}

Exponentiated coefficients; Standard errors in brackets $+\mathrm{p}<.05 * \mathrm{p}<.01 * * \mathrm{p}<.001$ 
TABLE 4. Likelihood Ratio Test Comparing Different Models

\begin{tabular}{|c|c|c|c|c|c|c|}
\hline \multirow[t]{3}{*}{ Restricted Model } & \multicolumn{3}{|c|}{ Unrestricted Model } & \\
\hline & & & & & Critical & \\
\hline & Log- & & Log- & & $\mathrm{p}<.01$ & \\
\hline Model (M) & Likelihood & Model (N) & Likelihood & $\mathrm{R}_{\mathrm{M}, \mathrm{N}}$ & Value & LR value \\
\hline Business registration information without Delaware & -2258.1 & Business Registration Information & -1792.7 & $20.61 \%$ & 6.63 & $930.80 * *$ \\
\hline Business Registration Information & -1792.7 & Intellectual Property and business registration & -1731.7 & $3.40 \%$ & 13.28 & $122.00 * *$ \\
\hline Business registration information without Delaware & -2258.1 & Intellectual Property and business registration without Delaware & -2094.01 & $7.27 \%$ & 9.21 & $328.18^{* *}$ \\
\hline Intellectual Property and Business Registration & -1731.7 & Media, IP, and Business Registration & -1712.1 & $1.13 \%$ & 6.63 & $39.20 * *$ \\
\hline Only Delaware Registration & -1978.9 & Media, IP, and Business Registration & -1712.1 & $13.48 \%$ & 23.21 & $533.54 * *$ \\
\hline Media, IP, and Business Registration & -1712.1 & Media, IP, Business Registration, and Founder Effects & -1712.0 & $0.01 \%$ & 9.21 & 0.20 \\
\hline
\end{tabular}


TABLE 5. OLS Regression on Ln(Growth) by Cohort Year and County

\begin{tabular}{|c|c|c|c|c|}
\hline & 1 & 2 & 3 & 4 \\
\hline \multirow[t]{3}{*}{$\operatorname{Ln}(\#$ of births) } & -0.0137 & & & \\
\hline & [0.0494] & & & \\
\hline & $(-0.277)$ & & & \\
\hline $\operatorname{Ln}($ Churn $)$ & & 0.0851 & & \\
\hline \multirow[t]{2}{*}{ Churn $=$ Births + Deaths } & & {$[0.0522]$} & & \\
\hline & & $(1.629)$ & & \\
\hline Quality & & & $0.234 * *$ & \\
\hline \multirow[t]{2}{*}{$\times 1000$ for readability } & & & [0.0609] & \\
\hline & & & $(3.837)$ & \\
\hline $\operatorname{Ln}(\mathrm{RECPI})$ & & & & $0.514 * *$ \\
\hline \multirow[t]{2}{*}{ RECPI $=$ Quality $\times \#$ of births } & & & & {$[0.168]$} \\
\hline & & & & $(3.059)$ \\
\hline County Fixed Effects & Yes & Yes & Yes & Yes \\
\hline $\mathrm{N}$ & 266 & 266 & 266 & 266 \\
\hline $\mathrm{R}^{2}$ & 0.794 & 0.796 & 0.809 & 0.808 \\
\hline
\end{tabular}

Robust standard errors in brackets. t-statistics in parenthesis. ${ }^{*} \mathrm{p}<0.05 * * \mathrm{p}<0.01$. 


\section{Figure 1}

Fig. 1. Estimated Entrepreneurial Quality Percentile vs. Incidence of Realized Growth Outcomes

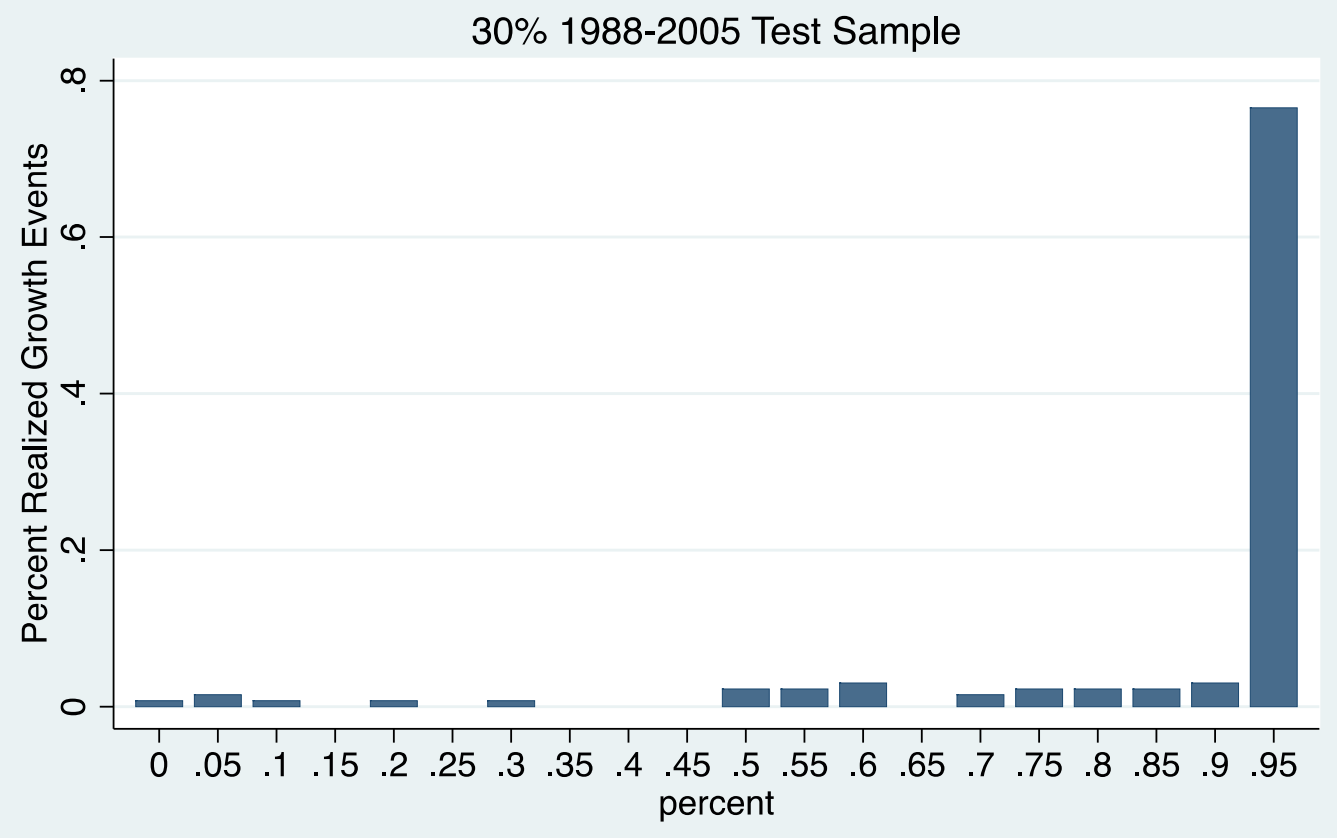


Fig. 2 (A) Growth Firms vs Firm Births By Cohort

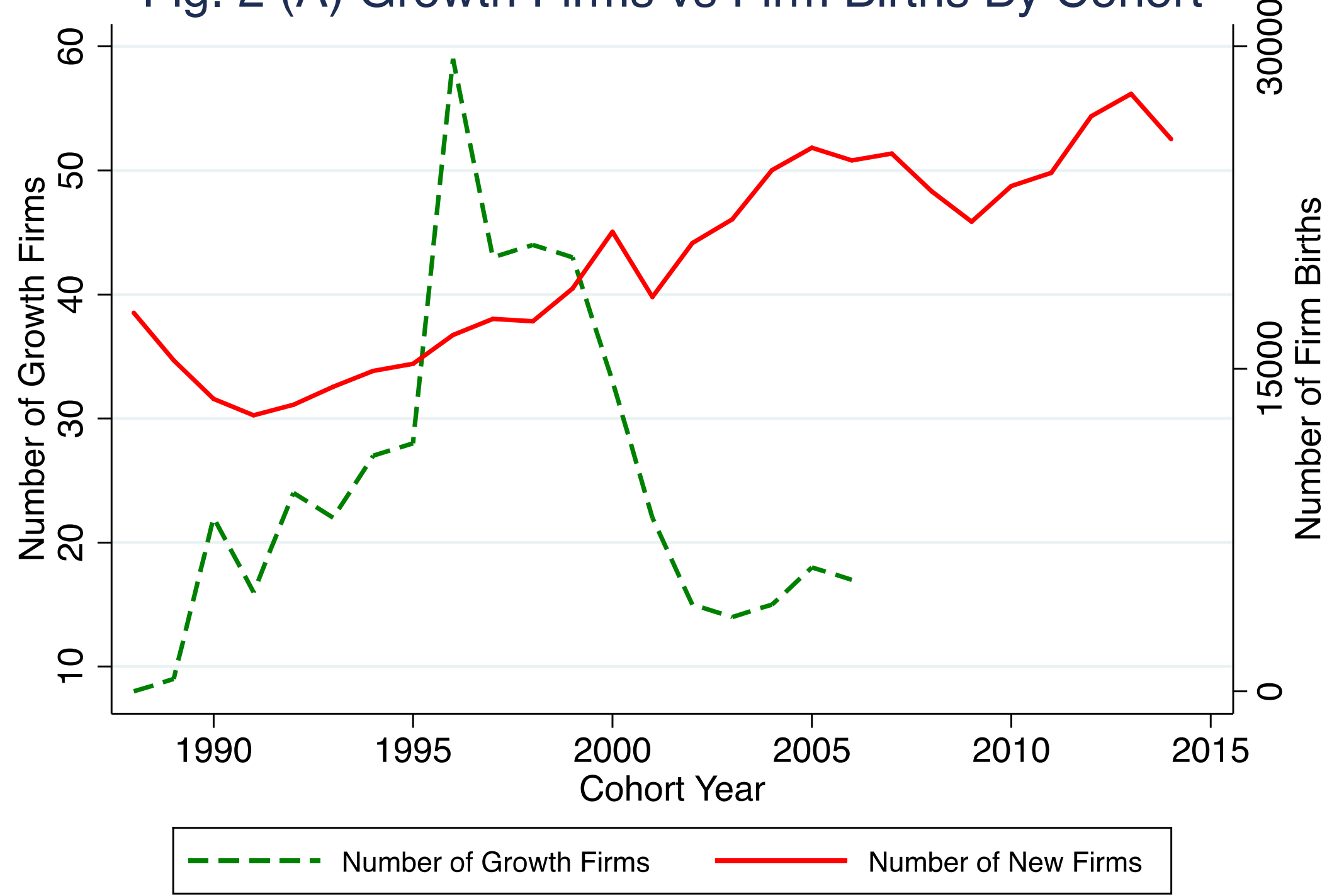


Fig. 2 (B) Regional Entrepreneurship Cohort Potential Index (RECPI)
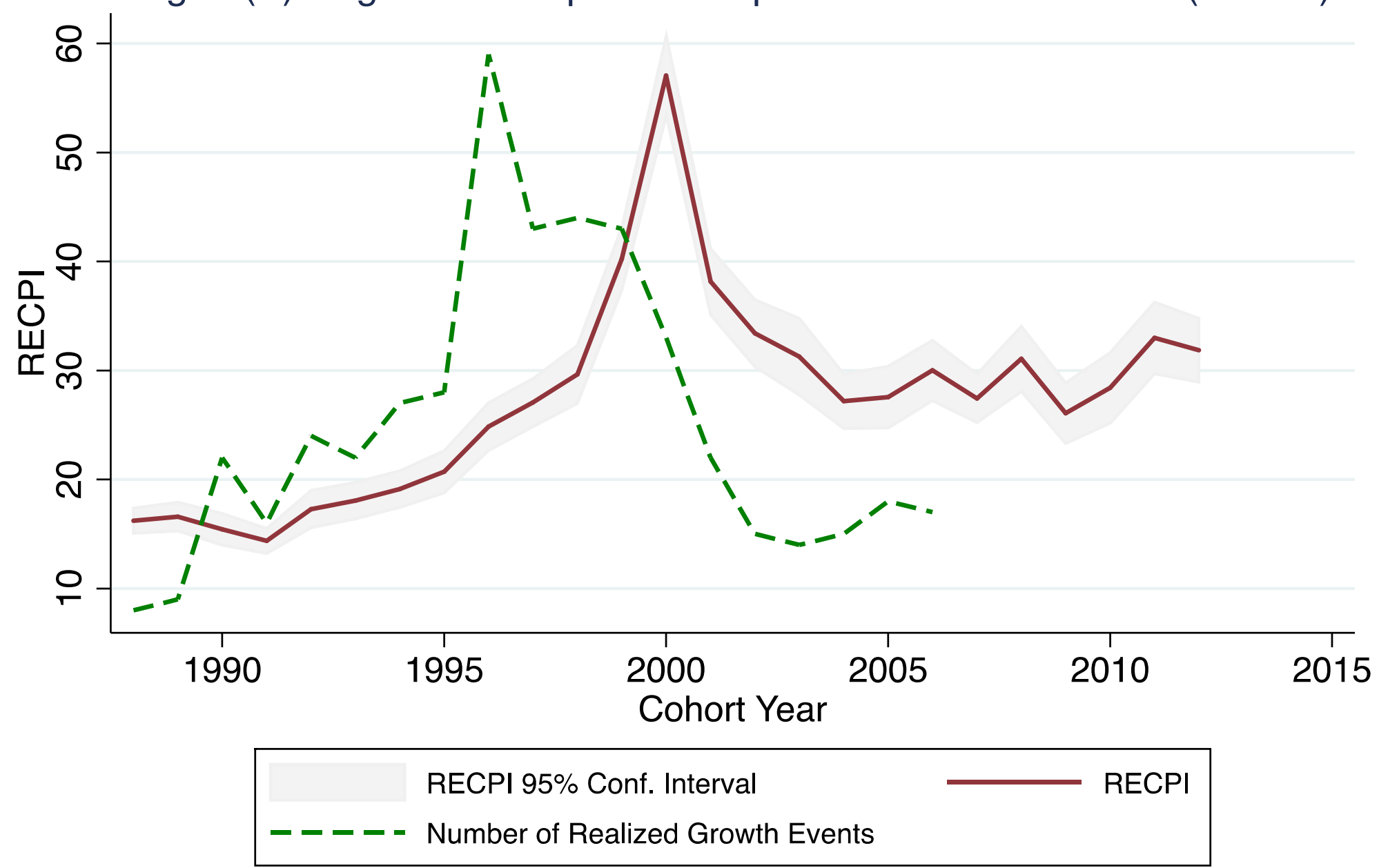

${ }^{*}$ RECPI standard error estimated through Penrose Square Root Law. (i.e., $\sigma_{\text {RECPI }}=\sigma_{E Q I}{ }^{*} \sqrt{ }(N)$ ) 


\section{Figure 3}

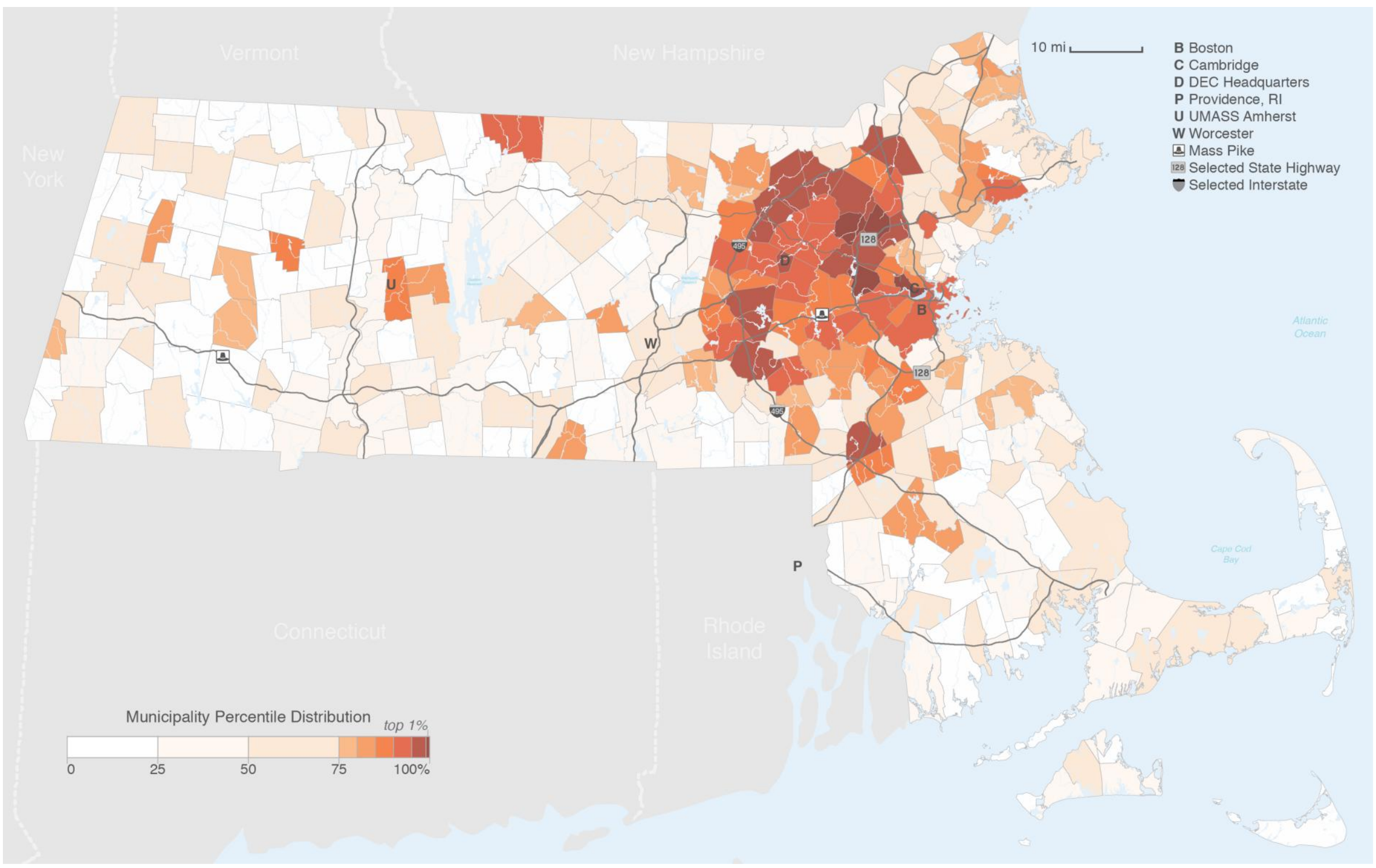


Figure 4. Entrepreneurship Quality Index (EQI) by County Top 5 Counties of 13 Total ( $95 \%$ of Growth Outcomes)

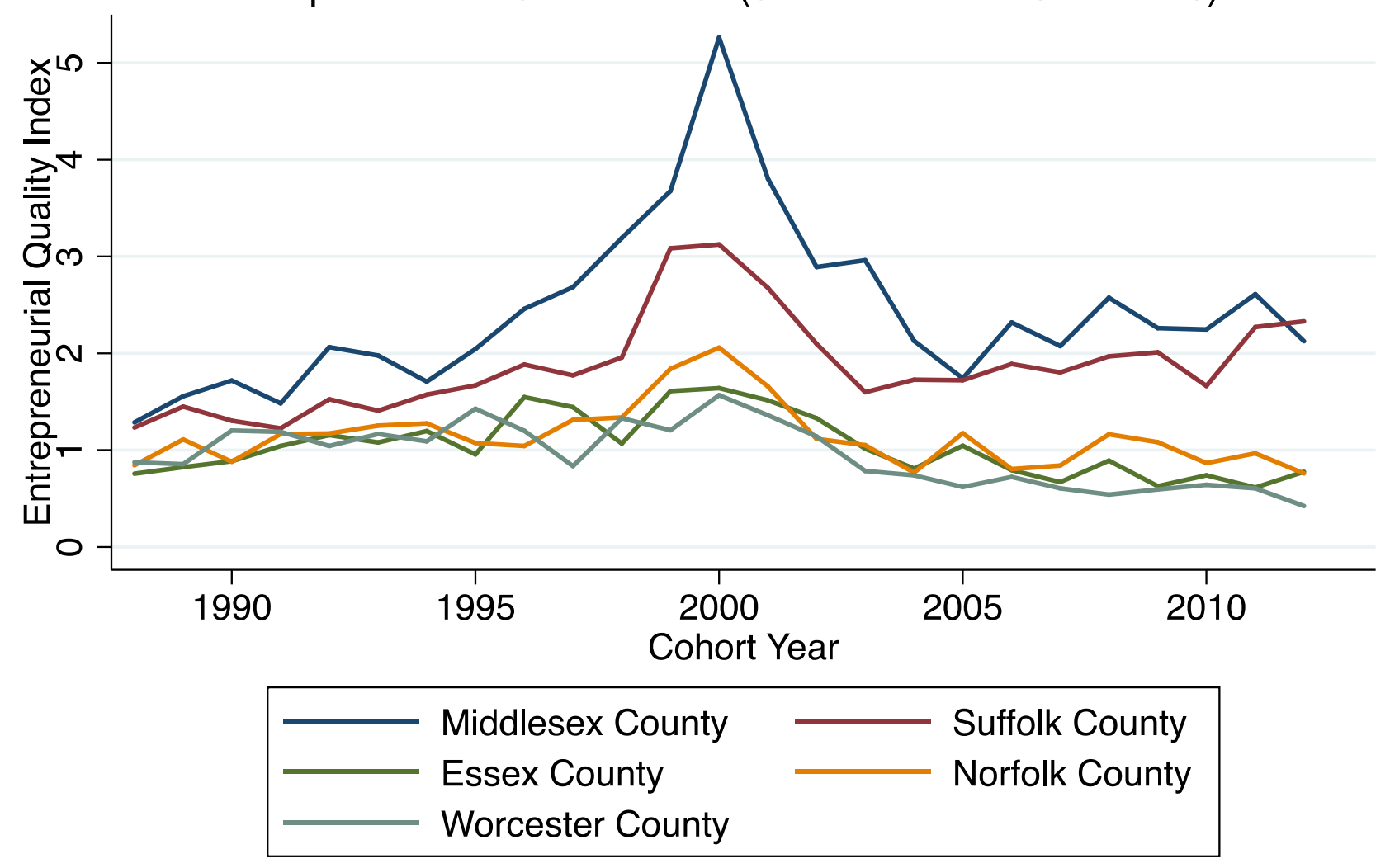


Fig. 5 RECPI for Select Cities

Route 128 v. Cambridge v. Boston

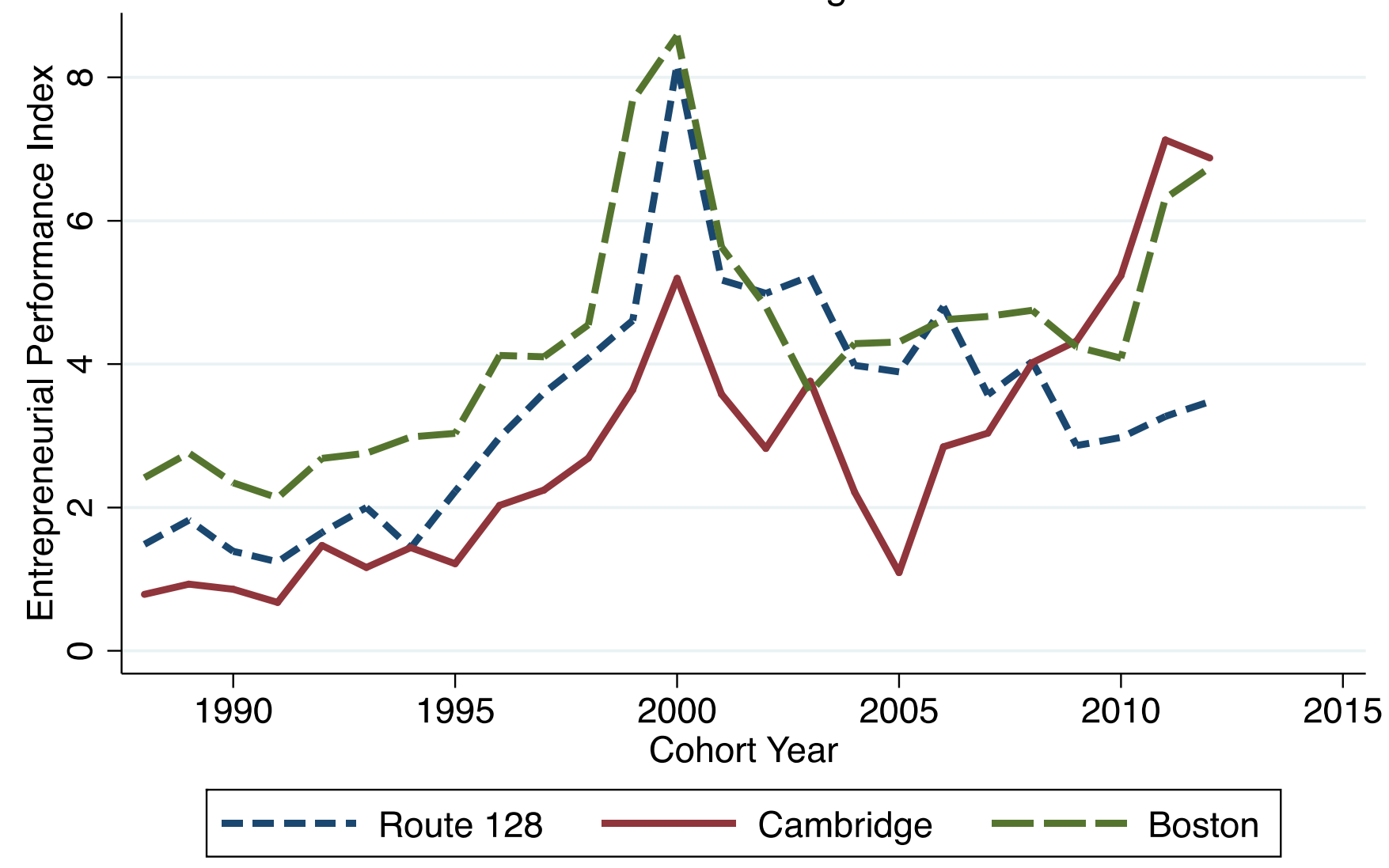




\section{FIGURE 6}

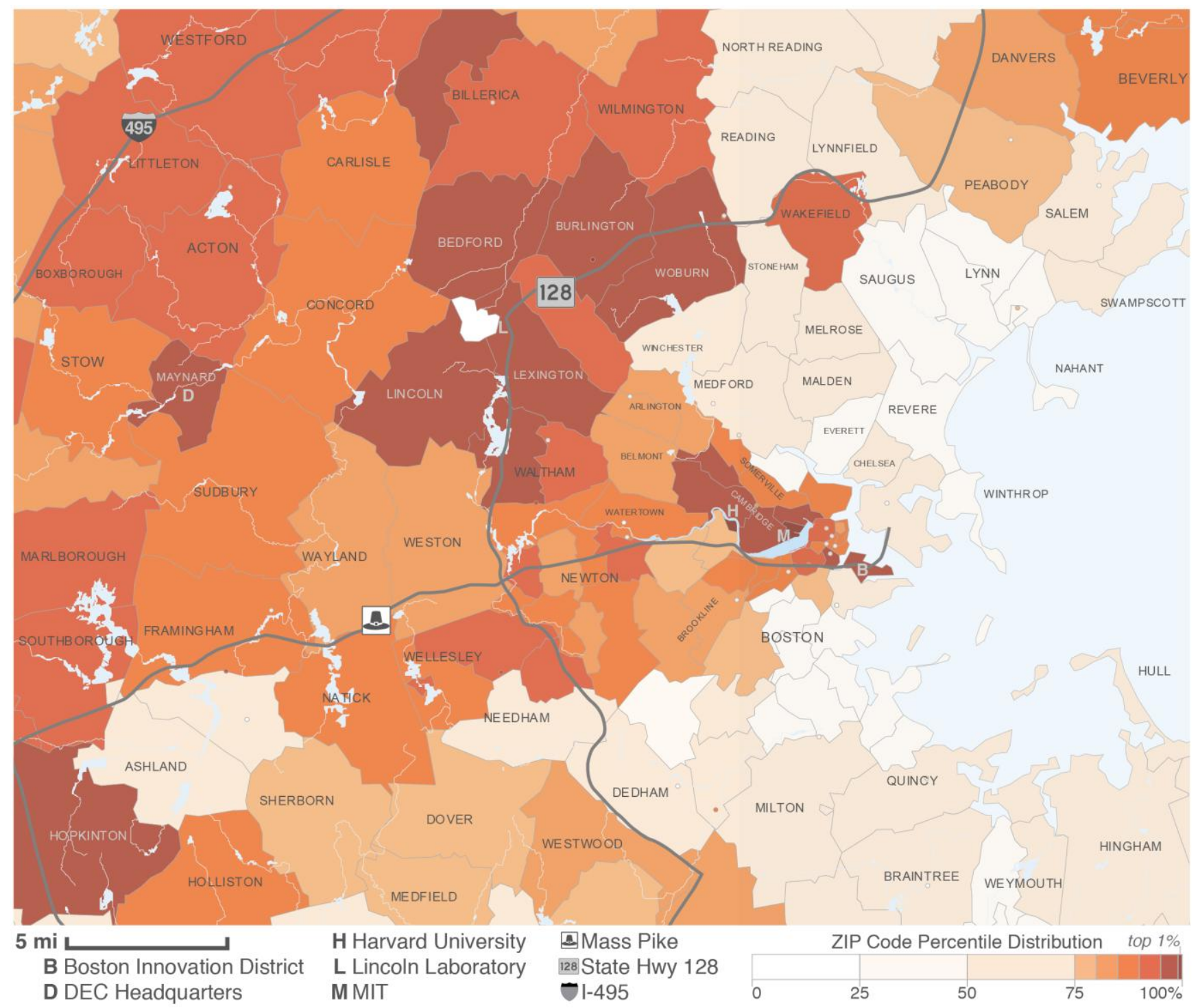


Fig. 7 Boston Area Growth Neighborhoods

MIT, Harvard, and Boston Innovation District

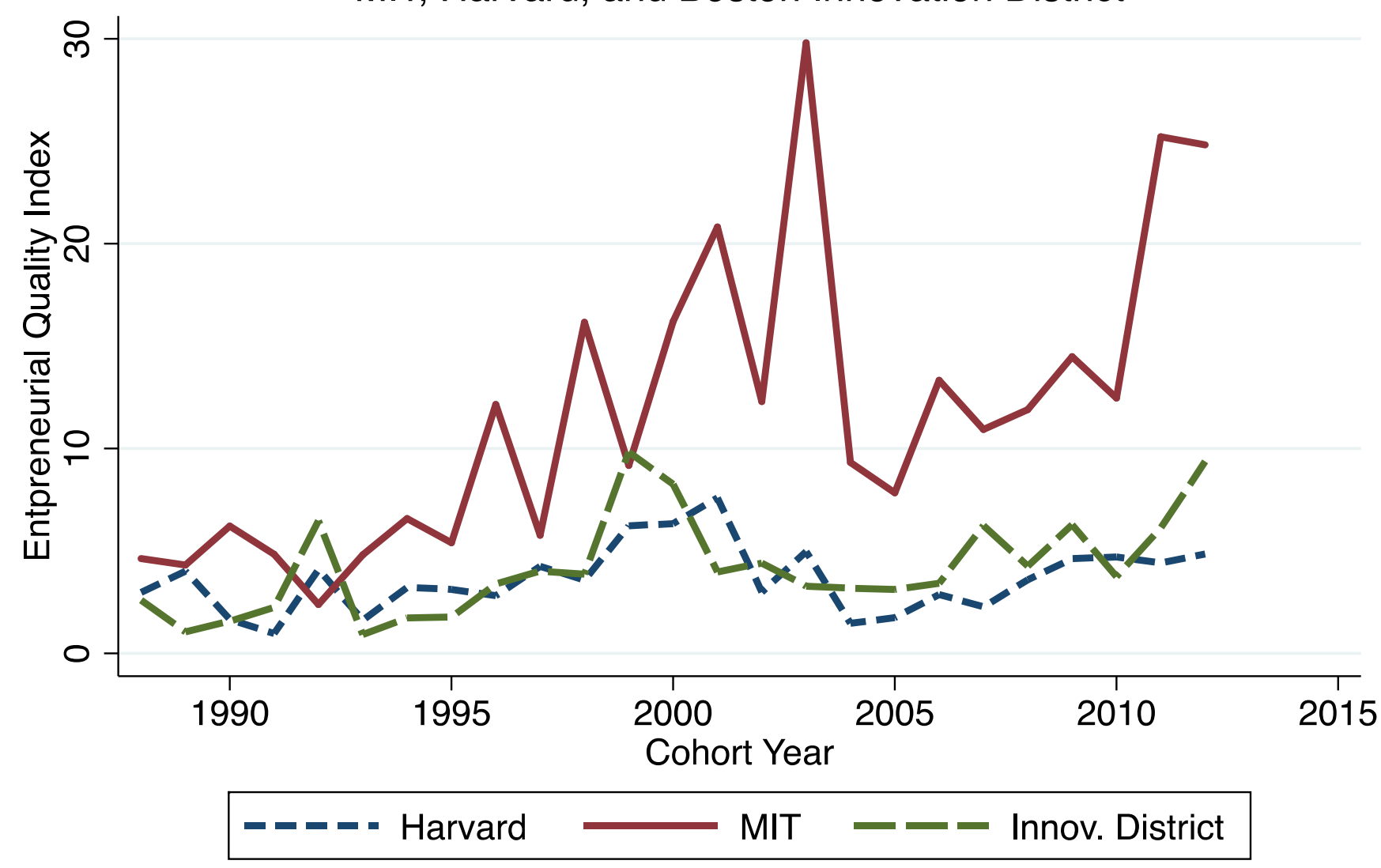


FIGURE 8

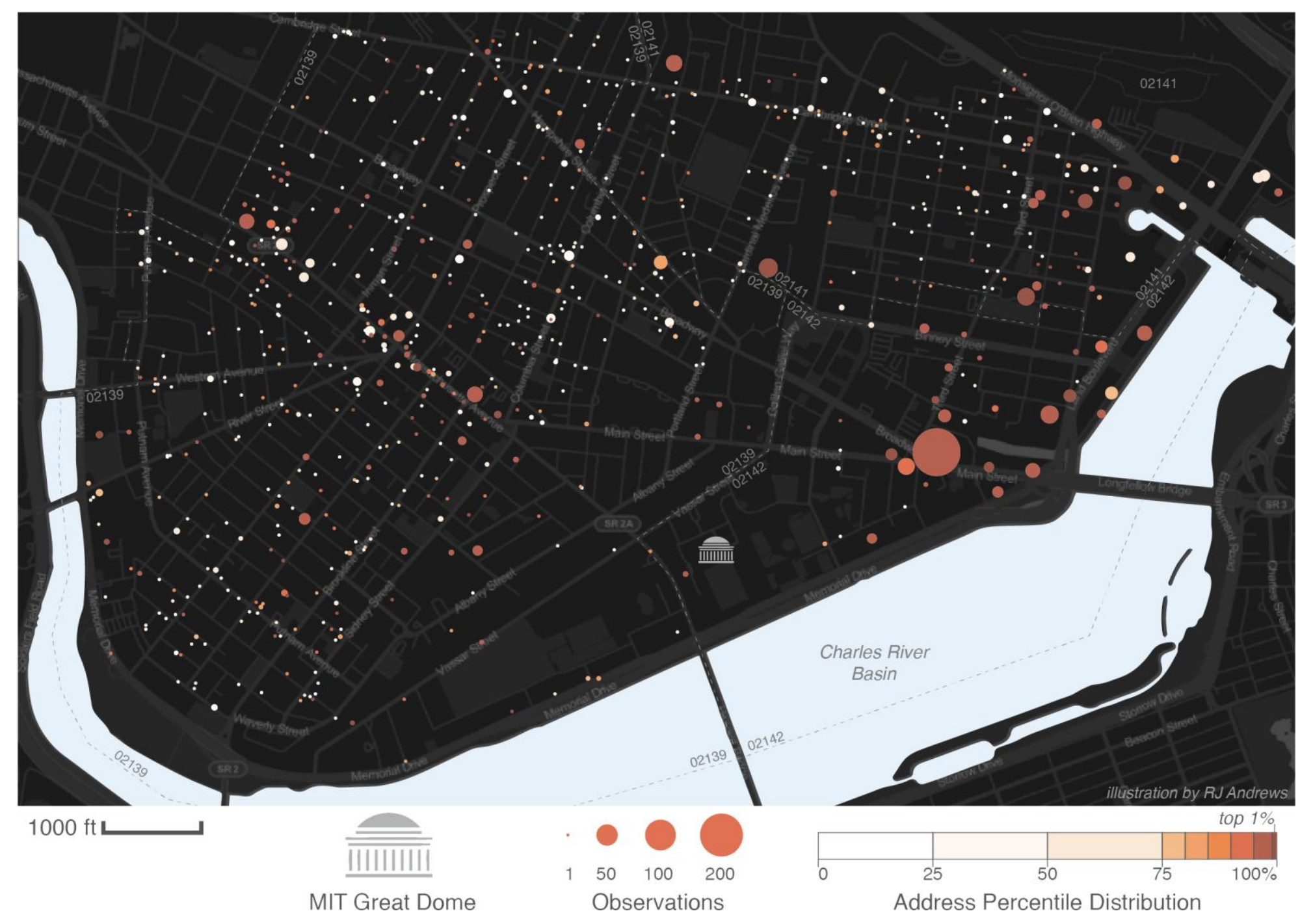


Fig. 9 (A) Nowcasted Massachusetts RECPI

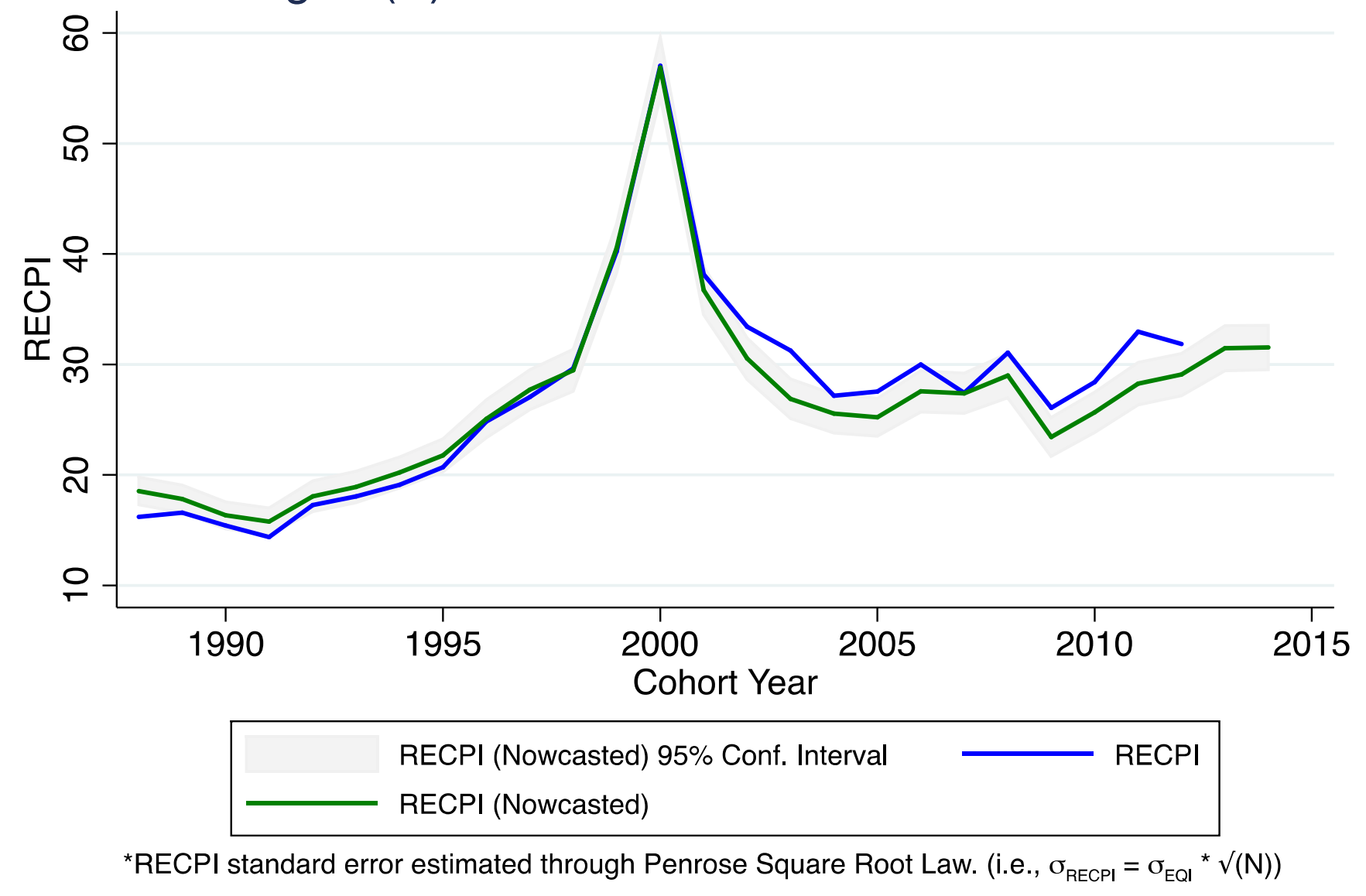


Fig. 9 (B) RECPI for Select Cities

Route 128 v. Cambridge v. Boston
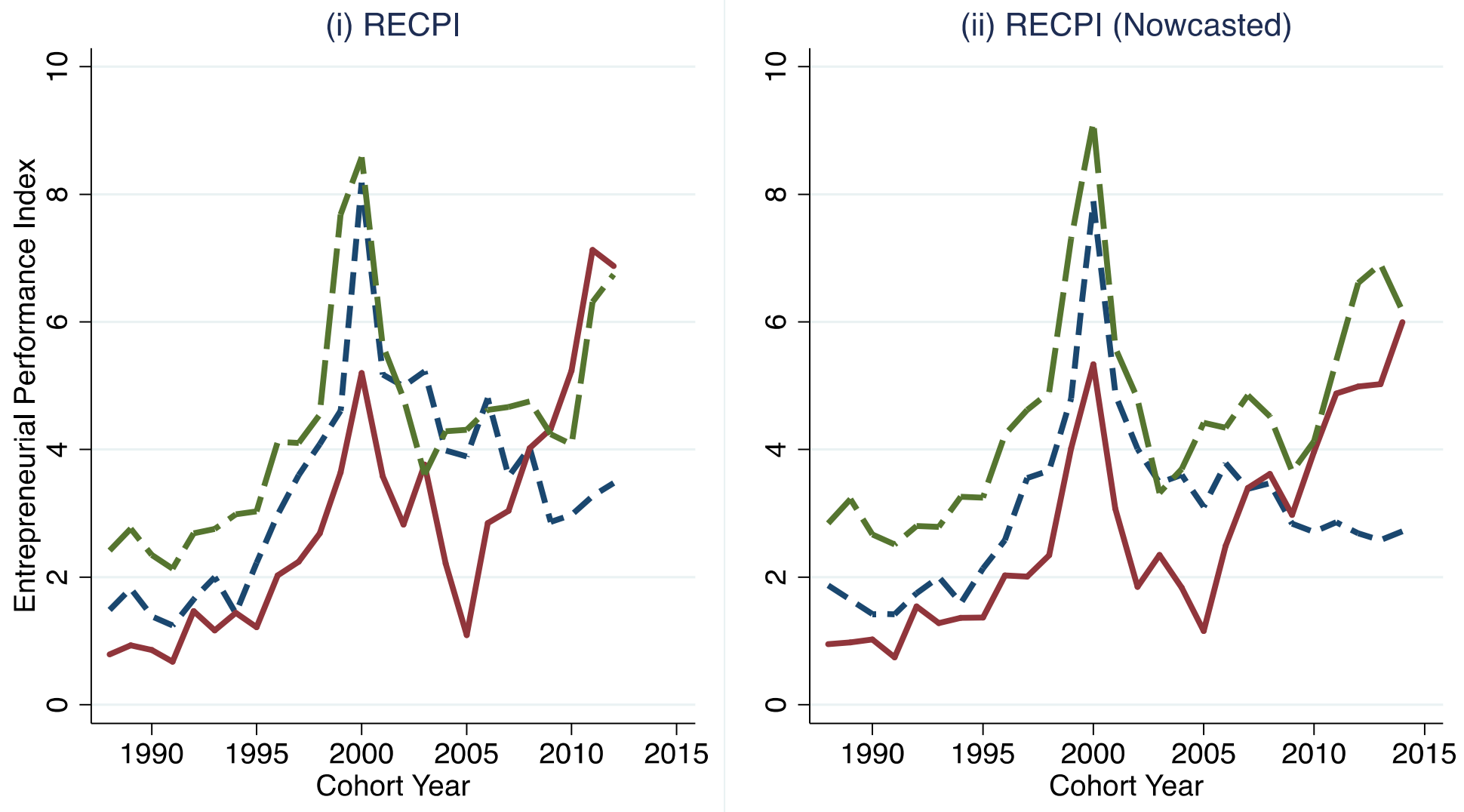

$$
\text { --ー-- Route } 128 \longrightarrow \text { Cambridge }- \text { Boston }
$$


Fig. 9 (C) Nowcasted Boston Area Growth Neighborhoods (EQI) MIT, Harvard, and Boston Innovation District
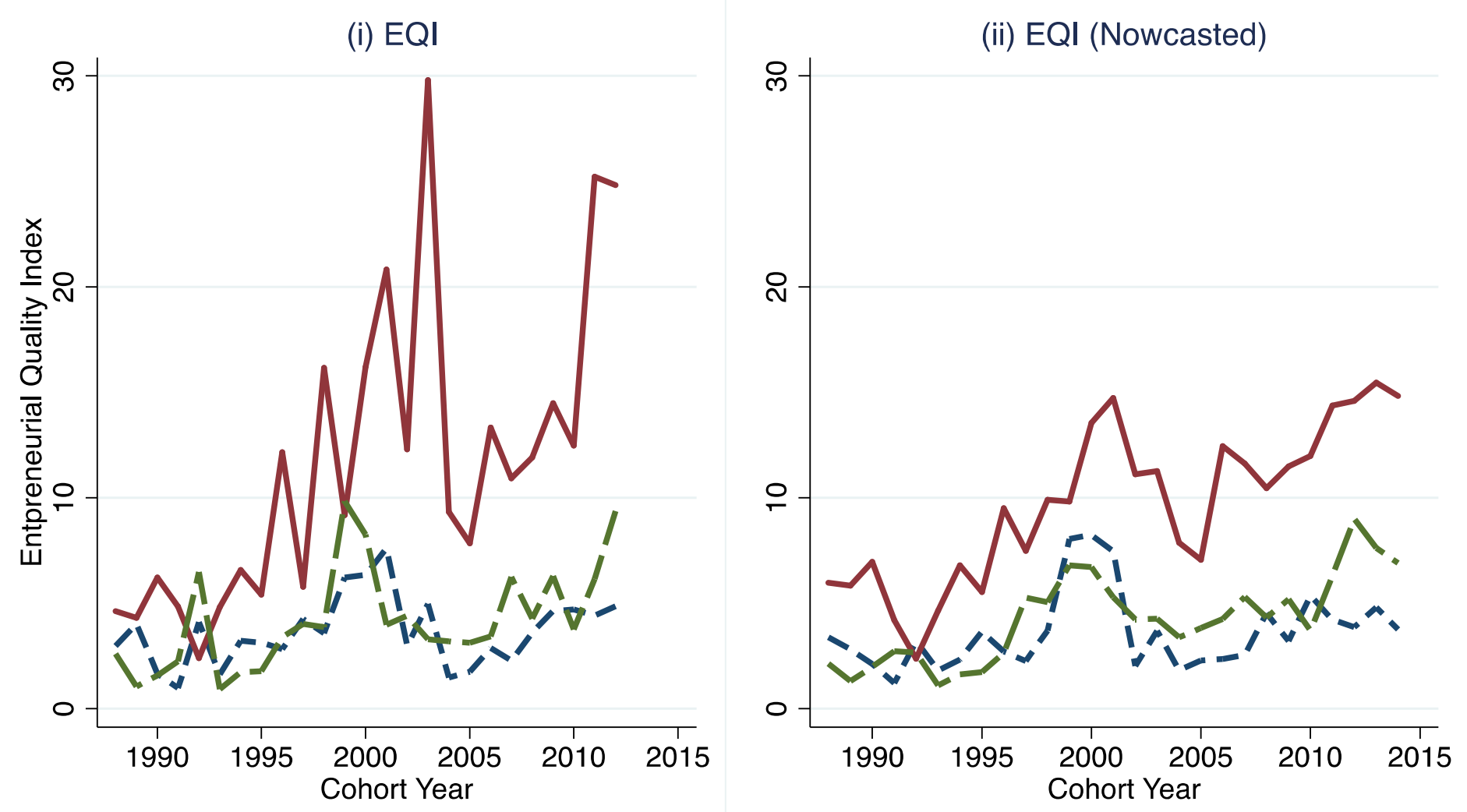

$$
\text { ---n: Harvard —MIT }=-- \text { Innov. District }
$$




\section{APPENDIX I. Massachusetts Business Registration Records}

Business registration records are a potentially rich and systematic data source for entrepreneurship and business dynamics. While it is possible to found a new business without business registration (e.g., a sole proprietorship), the benefits of registration are substantial, including limited liability, protection of the entrepreneur's personal assets, various tax benefits, the ability to issue and trade ownership shares, credibility with potential customers, and the ability to deduct expenses. Among business registrants, there are several categories, and the precise rules governing each categories vary by jurisdiction and time. This study focuses on the state of Massachusetts from 1988-2014, at which point one could register the following: corporations, limited liability companies, limited liability partnerships, limited partnerships, professional limited liability partnerships, and general partnerships (see (1) for further information).

The data in this paper comes from the Secretary of the Commonwealth of Massachusetts, Corporations Division (http://www.sec.state.ma.us/cor/coridx.htm, data received on November $27,2014)$ containing four files, a master file, containing a master record for all firms ever registered in Massachusetts at the moment of extraction; an individuals file, containing all the directors and titles of each firm; a name history file, with previous names of each firm; and a merger history file, with all mergers that have occurred in Massachusetts. The master file includes the following fields: firm id, tax status (non-profit or for profit), firm type (corporation, limited liability company, etc.), firm status (active, deceased, merged, etc.), jurisdiction (Massachusetts, or another US state), address, firm name, Massachusetts incorporation date, jurisdiction incorporation date (for foreign firms), address of the principal office (for firms 
foreign to California), and Doing Business As names. The individual file includes the following fields: firm id, title, first name, middle name, last name, business address and residential address. After combining these files, we generate unique firm identifiers. For this paper, we select a dataset of the for-profit firms first registered in Massachusetts from January 1, 1988 to November 25, 2014, satisfying one of the following two conditions: for-profit firms whose jurisdiction is Massachusetts, and for-profit Delaware firms whose main office is in Massachusetts. Table A1 lists the number of observations in our dataset for each annual cohort year from 1988 to 2014. It is useful to note that, for those firms registered in Delaware, we use the year they register in Delaware, not in Massachusetts, as their founding date. Both the links to the underlying data and the program files used to construct the dataset are available as requested from the authors.

As a final note, this paper uses a subset of the business registration records we have now gathered from several states, including California, Texas, Florida, Washington, and New York. Though our evaluation of Texas, Florida, Washington and New York is at a more preliminary stage, we have found very similar qualitative findings in terms of the impact of factors observable at or near the time of registration on subsequent growth outcomes, and the ability of these models to offer detailed characterization of growth entrepreneurship clusters. 


\section{TABLE A1}

\section{Number of Observations per Year}

\begin{tabular}{|c|c|c|c|}
\hline Year & $\mathrm{N}^{*}$ & Share of Total & Cumulative Share \\
\hline 1988 & 17,613 & $3.3 \%$ & $3.3 \%$ \\
\hline 1989 & 15,390 & $2.8 \%$ & $6.1 \%$ \\
\hline 1990 & 13,601 & $2.5 \%$ & $8.6 \%$ \\
\hline 1991 & 12,838 & $2.4 \%$ & $11.0 \%$ \\
\hline 1992 & 13,333 & $2.5 \%$ & $13.4 \%$ \\
\hline 1993 & 14,173 & $2.6 \%$ & $16.1 \%$ \\
\hline 1994 & 14,903 & $2.8 \%$ & $18.8 \%$ \\
\hline 1995 & 15,242 & $2.8 \%$ & $21.6 \%$ \\
\hline 1996 & 16,575 & $3.1 \%$ & $24.7 \%$ \\
\hline 1997 & 17,320 & $3.2 \%$ & $27.9 \%$ \\
\hline 1998 & 17,220 & $3.2 \%$ & $31.1 \%$ \\
\hline 1999 & 18,742 & $3.5 \%$ & $34.5 \%$ \\
\hline 2000 & 21,374 & $3.9 \%$ & $38.5 \%$ \\
\hline 2001 & 18,351 & $3.4 \%$ & $41.8 \%$ \\
\hline 2002 & 20,852 & $3.8 \%$ & $45.7 \%$ \\
\hline 2003 & 21,962 & $4.1 \%$ & $49.8 \%$ \\
\hline 2004 & 24,238 & $4.5 \%$ & $54.2 \%$ \\
\hline 2005 & 25,284 & $4.7 \%$ & $58.9 \%$ \\
\hline 2006 & 24,692 & $4.6 \%$ & $63.5 \%$ \\
\hline 2007 & 25,014 & $4.6 \%$ & $68.1 \%$ \\
\hline 2008 & 23,262 & $4.3 \%$ & $72.4 \%$ \\
\hline 2009 & 21,841 & $4.0 \%$ & $76.4 \%$ \\
\hline 2010 & 23,505 & $4.3 \%$ & $80.7 \%$ \\
\hline 2011 & 24,120 & $4.5 \%$ & $85.2 \%$ \\
\hline 2012 & 26,745 & $4.9 \%$ & $90.1 \%$ \\
\hline 2013 & 27,787 & $5.1 \%$ & $95.3 \%$ \\
\hline 2014 & 25,689 & $4.7 \%$ & $100.0 \%$ \\
\hline
\end{tabular}

$* \mathrm{~N}$ is the number of observations after limiting the sample to for-profit firms registered in Massachusetts and for-profit firms registered in Delaware with their main office in Massachusetts.

** The year 2014 only includes firms up to those registered on November, 24 of 2014. 


\section{APPENDIX II. Share of Entrepreneurship Performance by Region}

\begin{tabular}{lcc} 
County & Share of Entrepreneurship Performance & Share of Firm Births \\
\hline Middlesex County & $49.0 \%$ & $29.3 \%$ \\
\hline Suffolk County & $17.9 \%$ & $13.6 \%$ \\
\hline Norfolk County & $10.2 \%$ & $13.4 \%$ \\
\hline Essex County & $7.6 \%$ & $11.3 \%$ \\
\hline Worcester County & $5.6 \%$ & $9.5 \%$ \\
\hline Plymouth County & $3.0 \%$ & $7.1 \%$ \\
\hline Bristol County & $2.3 \%$ & $5.1 \%$ \\
\hline Hampden County & $1.7 \%$ & $4.4 \%$ \\
\hline Berkshire County & $0.8 \%$ & $1.6 \%$ \\
\hline Hampshire County & $0.7 \%$ & $1.4 \%$ \\
\hline Barnstable County & $0.7 \%$ & $1.9 \%$ \\
\hline Nantucket County & $0.2 \%$ & $0.6 \%$ \\
\hline Franklin County & $0.1 \%$ & $0.5 \%$ \\
\hline Dukes County & $0.1 \%$ & $0.4 \%$ \\
\hline
\end{tabular}




\section{APPENDIX III. Ranking of Entrepreneurial Quality by City}

Rank

\begin{tabular}{|c|c|}
\hline Citv & Oualitv \\
\hline CAMBRIDGE & 5.772 \\
\hline BEDFORD & 4.666 \\
\hline WALTHAM & 4.448 \\
\hline BURLINGTON & 4.320 \\
\hline LEXINGTON & 4.051 \\
\hline WOBURN & 3.397 \\
\hline MAYNARD & 3.392 \\
\hline BOXBOROUGH & 2.936 \\
\hline FOXBOROUGH & 2.707 \\
\hline LINCOLN & 2.617 \\
\hline HOPKINTON & 2.574 \\
\hline ANDOVER & 2.470 \\
\hline LITTLETON & 2.448 \\
\hline SOUTHBOROUGH & 2.434 \\
\hline BILLERICA & 2.433 \\
\hline MARLBOROUGH & 2.422 \\
\hline CHELMSFORD & 2.400 \\
\hline WESTFORD & 2.351 \\
\hline WESTBOROUGH & 2.259 \\
\hline ACTON & 2.219 \\
\hline BOLTON & 2.023 \\
\hline WAKEFIELD & 2.022 \\
\hline BOSTON & 1.984 \\
\hline WILMINGTON & 1.913 \\
\hline HOLLISTON & 1.896 \\
\hline WELLESLEY & 1.879 \\
\hline NEWTON & 1.874 \\
\hline CONCORD & 1.852 \\
\hline SUDBURY & 1.811 \\
\hline CARLISLE & 1.798 \\
\hline NATICK & 1.782 \\
\hline WATERTOWN & 1.620 \\
\hline BEVERLY & 1.592 \\
\hline ROYALSTON & 1.591 \\
\hline STOW & 1.581 \\
\hline NEEDHAM & 1.578 \\
\hline GOSHEN & 1.573 \\
\hline MANSFIELD & 1.535 \\
\hline HUDSON & 1.527 \\
\hline WENHAM & 1.475 \\
\hline AMHERST & 1.442 \\
\hline FRAMINGHAM & 1.433 \\
\hline NORTHBOROUGH & 1.418 \\
\hline CANTON & 1.417 \\
\hline BROOKLINE & 1.380 \\
\hline WESTWOOD & 1.371 \\
\hline BEILMONT & 1.370 \\
\hline WAYLAND & 1.333 \\
\hline WFSTON & 1.328 \\
\hline TEWKSBURY & 1.320 \\
\hline
\end{tabular}

Rank

Citv

HARVARD

ARLINGTON

SOMERVILLE

DALTON

DANVERS

NORWOOD

DOVER

FRANKLIN

GROTON

MEDFIELD

BERLIN

TAUNTON

NEWBURYPORT

SOUTHBRIDGE

WEST BRIDGEWATER

PAXTON

SHERBORN

SHARON

TOPSFIELD

PELHAM

CHESTER

NORWELL

ROCKLAND

MEDWAY

NEW BRAINTREE

AYER

MEDFORD

NEWBURY

WORTHINGTON

WINCHESTER

ALFORD

BRAINTREE

LUNENBURG

MARBLEHEAD

PEABODY

BOXFORD

GRAFTON

AMESBURY

ADAMS

LENOX

DEDHAM

NORTH ANDOVER

LEYDEN

SAVOY

WALPOLE

ASHLAND

MII.I.IS

WILLIAMSTOWN

HI JBRARDSTON

TYRINGHAM
Oualitv

1.316

1.302

1.285

1.262

1.227

1.194

1.151

1.085

1.085

1.082

1.081

1.080

1.071

1.068

1.053

1.049

1.044

1.024

1.020

1.017

1.016

1.005

1.004

0.998

0.996

0.978

0.974

0.964

0.951

0.938

0.938

0.930

0.926

0.920

0.917

0.916

0.912

0.911

0.895

0.893

0.888

0.888

0.881

0.878

0.874

0.874

0.871

0.867

0.861

0.861 


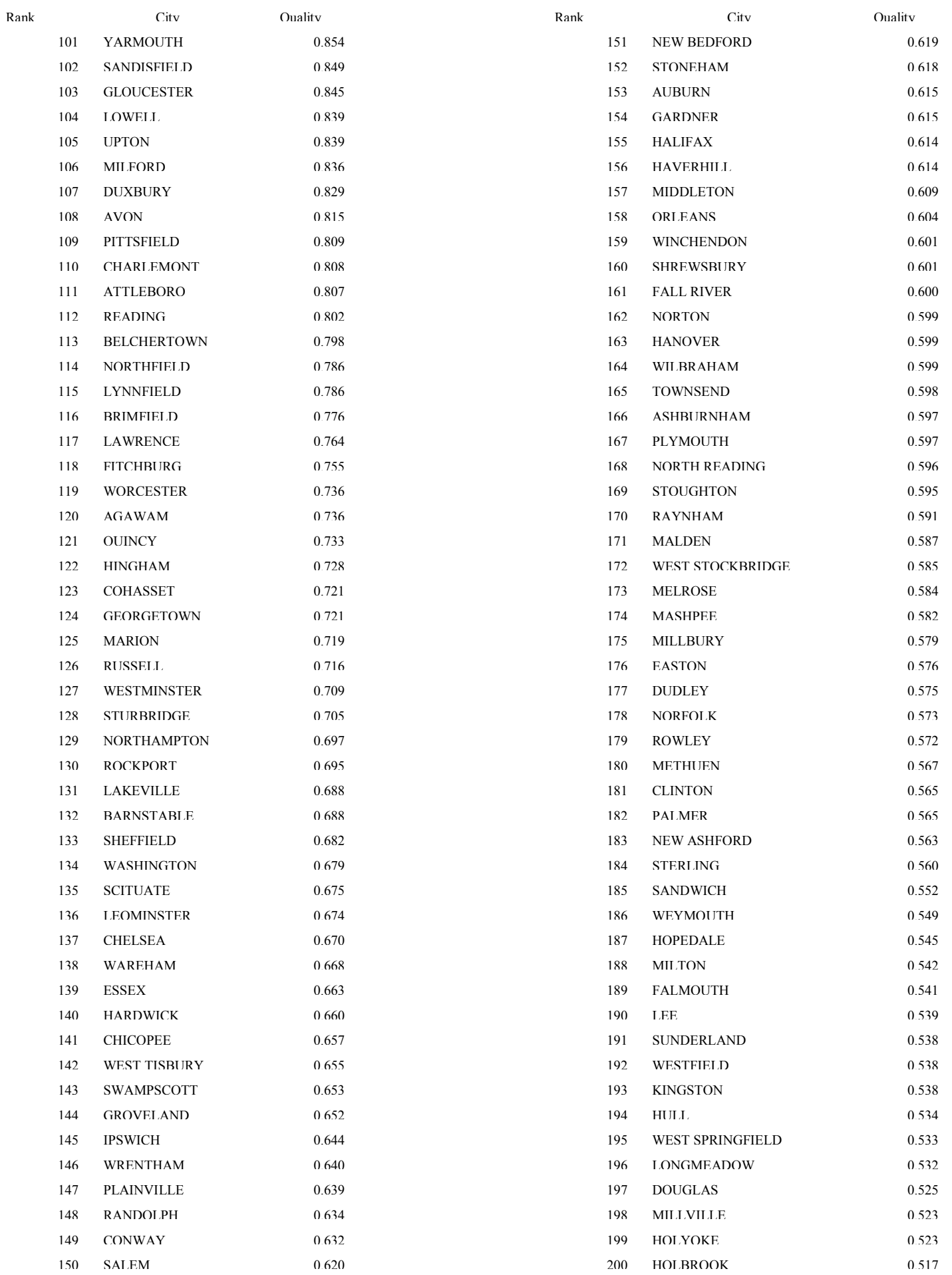




\begin{tabular}{|c|c|c|c|}
\hline \multirow[t]{2}{*}{ Rank } & & Citv & Oualitv \\
\hline & 201 & SPRINGFIFID & 0.516 \\
\hline & 202 & HANSON & 0.515 \\
\hline & 203 & OXFORD & 0.514 \\
\hline & 204 & WESTHAMPTON & 0.511 \\
\hline & 205 & ROCHESTER & 0.511 \\
\hline & 206 & MONTAGUE & 0.509 \\
\hline & 207 & RFHOBOTH & 0.509 \\
\hline & 208 & WEST BROOKFIELD & 0.506 \\
\hline & 209 & SOUTHWICK & 0.502 \\
\hline & 210 & MARSHFIELD & 0.494 \\
\hline & 211 & FASTHAMPTON & 0.490 \\
\hline & 212 & BOURNE & 0.488 \\
\hline & 213 & WFST NFWBI JRY & 0.487 \\
\hline & 214 & BELLINGHAM & 0.485 \\
\hline & 215 & MFNDON & 0.484 \\
\hline & 216 & TRURO & 0.480 \\
\hline & 217 & SAI ISBIJRY & 0.479 \\
\hline & 218 & RUTLAND & 0.478 \\
\hline & 219 & DENNIS & 0.477 \\
\hline & 220 & BOYLSTON & 0.477 \\
\hline & 221 & PEPPFRFIL & 0.476 \\
\hline & 222 & REVERE & 0.471 \\
\hline & 223 & ATHOI & 0.469 \\
\hline & 224 & PEMBROKE & 0.467 \\
\hline & 225 & SAIJGISS & 0.466 \\
\hline & 226 & DEERFIELD & 0.464 \\
\hline & 227 & NORTH ADAMS & 0.462 \\
\hline & 228 & TISBURY & 0.460 \\
\hline & 229 & MONSON & 0.457 \\
\hline & 230 & ABINGTON & 0.454 \\
\hline & 231 & SOMFRSET & 0.449 \\
\hline & 232 & SHIRLEY & 0.449 \\
\hline & 233 & PROVINCFTOWN & 0.448 \\
\hline & 234 & SWANSEA & 0.446 \\
\hline & 235 & EAST BROOKFIFID & 0.446 \\
\hline & 236 & HOLDEN & 0.444 \\
\hline & 237 & SPFNCER & 0.442 \\
\hline & 238 & MIDDLEBOROUGH & 0.437 \\
\hline & 239 & FDGARTOWN & 0.437 \\
\hline & 240 & WEBSTER & 0.434 \\
\hline & 241 & PETERSHAM & 0.432 \\
\hline & 242 & MERRIMAC & 0.431 \\
\hline & 243 & DI JNSTABI.F. & 0.430 \\
\hline & 244 & BARRE & 0.429 \\
\hline & 245 & I.ANCASTER & 0.429 \\
\hline & 246 & WARE & 0.428 \\
\hline & 247 & MANCHESTER-BY-THE-SEA & 0.422 \\
\hline & 248 & EAST LONGMEADOW & 0.421 \\
\hline & 249 & BERNARDSTON & 0.417 \\
\hline & 250 & NEW SALEM & 0.408 \\
\hline
\end{tabular}

\begin{tabular}{|c|c|c|c|}
\hline \multicolumn{2}{|l|}{ Rank } & Citv & Oualitv \\
\hline & 251 & GRFAT BARRINGTON & 0.406 \\
\hline & 252 & WESTPORT & 0.406 \\
\hline & 253 & TYNGSBOROUGH & 0.403 \\
\hline & 254 & CHILMARK & 0.402 \\
\hline & 255 & IIJDIOW & 0.401 \\
\hline & 256 & BROCKTON & 0.401 \\
\hline & 257 & SIJTTON & 0.400 \\
\hline & 258 & LYNN & 0.399 \\
\hline & 259 & HARWICH & 0.398 \\
\hline & 260 & DRACUT & 0.398 \\
\hline & 261 & SOITH HADI.FY & 0.397 \\
\hline & 262 & HADLEY & 0.390 \\
\hline & 263 & FAIRHAVEN & 0.389 \\
\hline & 264 & CARVER & 0.389 \\
\hline & 265 & CHARITON & 0.389 \\
\hline & 266 & PLYMPTON & 0.388 \\
\hline & 267 & BRIDGEWATER & 0.387 \\
\hline & 268 & WARREN & 0.386 \\
\hline & 269 & FASTHAM & 0.382 \\
\hline & 270 & WHITMAN & 0.382 \\
\hline & 271 & NANTIJCKET & 0.382 \\
\hline & 272 & EVERETT & 0.382 \\
\hline & 273 & I.FICESTER & 0.379 \\
\hline & 274 & NAHANT & 0.378 \\
\hline & 275 & IJXBRIDGE & 0.374 \\
\hline & 276 & MATTAPOISETT & 0.370 \\
\hline & 277 & СНАТНАМ & 0.368 \\
\hline & 278 & HAWLEY & 0.367 \\
\hline & 279 & WINTHROP & 0.364 \\
\hline & 280 & SOUTHAMPTON & 0.357 \\
\hline & 281 & GRFFNFIFID & 0.353 \\
\hline & 282 & HAMILTON & 0.348 \\
\hline & 283 & STOCKBRIDGF. & 0.348 \\
\hline & 284 & HATFIELD & 0.347 \\
\hline & 285 & WIIJIJAMSBIJRG & 0.339 \\
\hline & 286 & WENDELL & 0.339 \\
\hline & 287 & NORTHBRIDGF & 0.335 \\
\hline & 288 & WALES & 0.328 \\
\hline & 289 & BRFWSTFR & 0.328 \\
\hline & 290 & SEEKONK & 0.326 \\
\hline & 291 & ASHBY & 0.324 \\
\hline & 292 & WEST BOYLSTON & 0.322 \\
\hline & 293 & GRANBY & 0.316 \\
\hline & 294 & HAMPDEN & 0.316 \\
\hline & 295 & HOI.I.AND & 0.315 \\
\hline & 296 & DARTMOUTH & 0.311 \\
\hline & 297 & MONTEREY & 0.310 \\
\hline & 298 & DIGHTON & 0.310 \\
\hline & 299 & FLORIDA & 0.309 \\
\hline & 300 & NEW MARLBOROUGH & 0.307 \\
\hline
\end{tabular}




\begin{tabular}{|c|c|c|c|}
\hline \multirow[t]{2}{*}{ Rank } & & Citv & Oualitv \\
\hline & 301 & CHESHIRE & 0.306 \\
\hline & 302 & BLACKSTONE & 0.305 \\
\hline & 303 & I.FVFRETT & 0.302 \\
\hline & 304 & ORANGE & 0.301 \\
\hline & 305 & BUCKI.AND & 0.299 \\
\hline & 306 & ACUSHNET & 0.297 \\
\hline & 307 & WFIIIFIFFT & 0.293 \\
\hline & 308 & SHUTESBURY & 0.293 \\
\hline & 309 & CI.ARKSBIJRG & 0.291 \\
\hline & 310 & BECKET & 0.290 \\
\hline & 311 & AOUINNAH & 0.287 \\
\hline & 312 & CHESTERFIELD & 0.284 \\
\hline & 313 & BROOKFIFID & 0.284 \\
\hline & 314 & HINSDALE & 0.281 \\
\hline & 315 & PRINCETON & 0.278 \\
\hline & 316 & EAST BRIDGEWATER & 0.277 \\
\hline & 317 & PHII.JIPSTON & 0.271 \\
\hline & 318 & COLRAIN & 0.265 \\
\hline & 319 & NORTH ATTI.FBOROIJGH & 0.264 \\
\hline & 320 & RICHMOND & 0.262 \\
\hline & 321 & FRVING & 0.256 \\
\hline & 322 & EGREMONT & 0.256 \\
\hline & 323 & HINTINGTON & 0.253 \\
\hline & 324 & OAKHAM & 0.252 \\
\hline & 325 & OAK BIJJFFS & 0.252 \\
\hline & 326 & MOUNT WASHINGTON & 0.249 \\
\hline & 327 & BERKI.EY & 0.246 \\
\hline & 328 & GILL & 0.245 \\
\hline & 329 & I. ANFSBOROUGH & 0.243 \\
\hline & 330 & WHATELY & 0.241 \\
\hline & 331 & TEMPI.FTON & 0.235 \\
\hline & 332 & NORTH BROOKFIELD & 0.235 \\
\hline & 333 & BI.ANDFORD & 0.234 \\
\hline & 334 & WARWICK & 0.234 \\
\hline & 335 & ASHFIEID & 0.232 \\
\hline & 336 & CUMMINGTON & 0.228 \\
\hline & 337 & OTIS & 0.228 \\
\hline & 338 & PLAINFIELD & 0.227 \\
\hline & 339 & WINDSOR & 0.218 \\
\hline & 340 & TOLLAND & 0.218 \\
\hline & 341 & GRANVIII.F & 0.215 \\
\hline & 342 & SHELBURNE & 0.212 \\
\hline & 343 & HFATH & 0.211 \\
\hline & 344 & MONTGOMERY & 0.210 \\
\hline & 345 & HANCOCK & 0.204 \\
\hline & 346 & ROWE & 0.199 \\
\hline & 347 & PERU & 0.193 \\
\hline & 348 & FREETOWN & 0.189 \\
\hline & 349 & MIDDLEFIELD & 0.146 \\
\hline
\end{tabular}


